TI 2012-114/IV

Tinbergen Institute Discussion Paper
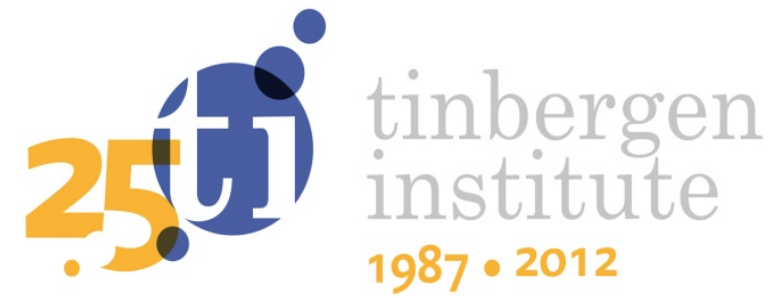

\title{
Top Incomes, Rising Inequality, and Welfare
}

Kevin J. Lansing

Agnieszka Markiewicz²

' FRB San Francisco and Norges Bank;

2 Erasmus School of Economics, Erasmus University Rotterdam, and Tinbergen Institute. 
Tinbergen Institute is the graduate school and research institute in economics of Erasmus University Rotterdam, the University of Amsterdam and VU University Amsterdam.

More TI discussion papers can be downloaded at http://www.tinbergen.nl

Tinbergen Institute has two locations:

Tinbergen Institute Amsterdam

Gustav Mahlerplein 117

1082 MS Amsterdam

The Netherlands

Tel.: +31(0)205251600

Tinbergen Institute Rotterdam

Burg. Oudlaan 50

3062 PA Rotterdam

The Netherlands

Tel.: +31(0)10 4088900

Fax: $+31(0) 104089031$

Duisenberg school of finance is a collaboration of the Dutch financial sector and universities, with the ambition to support innovative research and offer top quality academic education in core areas of finance.

DSF research papers can be downloaded at: http://www.dsf.nl/

Duisenberg school of finance

Gustav Mahlerplein 117

1082 MS Amsterdam

The Netherlands

Tel.: +31(0)20 5258579 


\title{
Top Incomes, Rising Inequality, and Welfare*
}

\author{
Kevin J. Lansing ${ }^{\dagger}$ \\ FRB San Francisco
}

\author{
Agnieszka Markiewicz $z^{\ddagger}$ \\ Erasmus University Rotterdam
}

April 28, 2015

\begin{abstract}
We introduce permanently-shifting income shares into a standard growth model with two types of agents. Capital owners represent the top quintile of U.S. households while workers represent the remainder. Our tractable model allows us to exactly replicate the observed U.S. time paths of the top quintile income share, capital's share of income, and key macroeconomic variables over the period 1970 to 2013. For the baseline simulation, the welfare gain for capital owners is $3.7 \%$ of per-period consumption while workers suffer a welfare loss of $1.4 \%$. Using counterfactual simulations, we find that both groups could have achieved gains if redistributive government transfers had increased to around $18 \%$ of total output by the year 2013 - somewhat higher than the actual value of around $15 \%$ observed in the data.
\end{abstract}

Keywords: Top Incomes, Inequality, Distribution shocks, Redistributive Transfer Payments, Welfare.

JEL Classification: D31, E32, E44, H21, O33.

${ }^{*}$ For helpful comments and suggestions, we would like to thank three anonymous referees, Baris Kaymak, Dirk Krueger, Morten Ravn, Kjetil Storesletten, Jacek Suda, and seminar participants at Erasmus University Rotterdam, Norges Bank, Sveriges Riksbank, University of Oslo, the National Bank of Poland, the 2014 Winter Meeting of the Econometrics Society, the 2013 Canadian Macroeconomics Study Group, the 2013 meeting of the European Economics Association, the 2012 International Conference on Inequalities, Skills, and Globilization, and the 2012 Workshop on Inequality and Macroeconomic Performance sponsored by OFCE and Skema Business School. Part of this research was conducted while Lansing was a visiting economist at the Norges Bank, whose hospitality is gratefully acknowledged.

${ }^{\dagger}$ Corresponding author. Research Department, Federal Reserve Bank of San Francisco, P.O. Box 7702, San Francisco, CA 94120-7702, email: kevin.j.lansing@sf.frb.org

${ }^{\ddagger}$ Erasmus University Rotterdam, P.O. Box 1738, 3000 DR Rotterdam, the Netherlands, email: markiewicz@ese.eur.nl 


\section{Introduction}

Income inequality in the U.S. economy has increased markedly over the past several decades. Most of the increase can be traced to gains made by those near the top of the income distribution. As noted by Piketty (2014), p. 297 "if we consider the total growth of the U.S. economy in the thirty years prior to the crisis, that is, from 1977 to 2007, we find that the richest 10 percent appropriated three-quarters of the growth." The top left panel of Figure 1 shows the dramatic upward shift in the share of pre-tax income going to the top decile of U.S. households, as compiled by Piketty and Saez $(2003,2013 a) .{ }^{1}$ Using data from the U.S. Census Bureau, the top right panel shows that the pre-tax income share of the top quintile of U.S. households increased by 8 percentage points, going from $43 \%$ in 1970 to $51 \%$ in 2013 . Also using U.S. Census data, the bottom left panel of Figure 1 shows that the growth in mean household income has significantly outpaced the growth in the median income since 1970. This pattern indicates a shift in the mass of income towards the upper tail of the distribution. ${ }^{2}$

The bottom right panel shows that capital's share of income increased from about $35 \%$ in 1970 to almost $44 \%$ in $2013 .^{3}$ Given that the distribution of wealth in the U.S. economy is highly skewed, the increase in capital's share of income would be expected to disproportionately benefit households near the top of the income distribution. ${ }^{4}$ As a mitigating factor, transfer payments from the government to individuals increased from $7.4 \%$ of output in 1970 to $14.6 \%$ in 2013. These transfers would be expected to disproportionately benefit households outside the top quintile of the income distribution. ${ }^{5}$

Motivated by the above observations, this paper develops a quantitative growth model to assess the welfare consequences of rising U.S. income inequality since 1970. The model includes two types of infinitely-lived agents: capital owners who represent the top income quintile of U.S. households and workers who represent the remainder. All agents supply labor inelastically to firms. Our setup is similar to other concentrated capital ownership models

\footnotetext{
${ }^{1}$ Updated annual data are available from The World Top Incomes Database.

${ }^{2}$ Census income is defined as income received on a regular basis (exclusive of capital gains) before payments for personal income taxes, social security, union dues, medicare deductions, food stamps, subsidized housing, etc. The data plotted in Figure 1 are from Tables H-2 and H-17 at www.census.gov/hhes/www/income/data/historical/household/.

${ }^{3}$ Following Lansing (2015), capital's share of income is measured as 1 minus the ratio of employee compensation to gross value added of the corporate business sector. Both series are from the Bureau of Economic Analysis (BEA), NIPA Table 1.14, lines 1 and 4.

${ }^{4}$ The increase in capital's share is not limited to the United States. Using data over the period 1975 to 2012, Karabarbounis and Neiman (2014) find that capital's share increased in 42 out of 59 countries with at least 15 years of data.

${ }^{5}$ Transfers include benefits from Old Age, Survivors, and Disability Insurance (OASDI), Medicare and Medicaid benefits, Supplemental Security Income, Family Assistance, Food Stamps, and Unemployment Insurance Compensation.
} 
that have been applied successfully to asset pricing. ${ }^{6}$

The top income quintile in our model owns 100 percent of the productive capital stock - a setup that roughly approximates the highly-skewed distribution of U.S. financial wealth. Using data from the Survey of Consumer Finances, Wolff (2010, p.44) finds that the share of total financial wealth owned by the top quintile of U.S. households remained steady at around 92 percent from 1983 to 2007. Shares of corporate stock are an important component of financial wealth, representing claims to the physical capital of firms. As recently as 1995, the lowest 75 percent of U.S. households sorted by wealth owned less than 10 percent of stocks. ${ }^{7}$

Our tractable economic model delivers approximate decision rules for consumption and investment that depend on income share variables, distortionary tax wedges, and the level of real output. The income share variables enter the model via stochastic exponents in a Cobb-Douglas aggregate production function, along the lines of Young (2004), Ríos-Rull and Santaeulàlia-Llopis (2010), and Lansing (2015). But in contrast to these papers, we assume that the exponent shifts are permanent rather than temporary. Our modeling strategy is similar to Goldin and Katz (2007) who allow for permanent shifts in the share parameters of a constant elasticity of substitution production function as a way of capturing technologyinduced changes in the demand for skilled versus unskilled labor. Here we remain agnostic about the underlying causes of the production function shifts and focus on the resulting consequences for welfare. Tax wedges enter the model via the budget constraints of the agents and the government. We allow for a distortionary income tax and a variable that governs the fraction of investment that can be "expensed," or immediately deducted from taxable income.

As inputs to the model, we incorporate the observed U.S. time paths of the top quintile income share and capital's share of total income, as plotted in the right panels of Figure 1. Given these time paths from the data, we solve for time series of (unobservable) tax wedges and productivity shocks so that the model exactly replicates the observed trajectories of the following U.S. macroeconomic variables over the period 1970 to 2013: (1) real per capital output, (2) real per capita aggregate consumption, (3) real per capita nonresidential private investment, (4) real per capita government consumption and investment, and (5) real per capita government transfer payments to individuals. ${ }^{8}$ Figure 2 plots the latter four variables as ratios relative to real output. ${ }^{9}$

\footnotetext{
${ }^{6}$ See, for example, Danthine, Donaldsen, and Siconolfi (2008), Guvenen (2009), and Lansing (2015).

${ }^{7}$ See Heaton and Lucas (2000), Figure 3, p. 224.

${ }^{8}$ Our methodology is conceptullally similar to that of Chari, McGrattan, and Kehoe (2007) who develop a quantitative model with four "wedges" that relate to labor, investment, productivity, and government consumption.

${ }^{9}$ Nominal personal consumption expenditures are from the Bureau of Economic Analysis, NIPA Table 2.3.5. The corresponding price index is from Table 1.1.4. Nominal government consumption and investment and the corresponding price index are from NIPA Tables 1.1.5 and 1.1.4. Nominal private nonresidential fixed investment and the corresponding implicit price deflator are from the Federal Reserve Bank of St. Louis' FRED database.
} 
Given time series for the income shares, tax wedges, and productivity shocks, we use the model's decision rules to construct individual consumption paths for the capital owners and workers. Our procedure ensures that the individual consumption paths that we use to evaluate welfare are consistent with the evolution of the U.S. macro variables over the period 1970 to 2013.

Welfare effects are measured by the percentage change in per-period consumption that makes each type of agent indifferent between the baseline simulation and a counterfactual scenario in which income shares and the transfer-output ratio are held constant at year 1970 values. Both scenarios employ the same time series of distortionary tax wedges and productivity shocks to isolate the effects of rising income inequality, as opposed to changes in tax policy or changes in the business cycle. An advantage of our quantitative modeling approach is that it allows us to construct a clean counterfactual scenario. In contrast, a purely empirical analysis based on ex post observed U.S. data cannot take into account how the economy would have evolved in the absence of shifting income shares and rising transfer payments.

For the baseline model simulation, the welfare gain for capital owners is $3.7 \%$ of their perperiod consumption while workers suffer a welfare loss of $1.4 \%$ of their per period consumption. These results reflect changes in the time pattern of consumption for each type of agent in both the short-run and the long-run. Due to discounting, the short-run changes in consumption are more important for welfare. From 1970 to 2013, consumption growth for capital owners exhibits a higher mean and a lower volatility relative to the counterfactual. In the long-run, the capital owner's consumption undergoes a permanent upward level shift of $22.4 \%$ relative to the counterfactual scenario.

The worker's consumption falls below the counterfactual path during a substantial portion of the period from 1970 to 2013. But much later in the simulation, around the year 2040, the worker's consumption actually surpasses the counterfactual path, eventually leading to a permanent upward level shift of $10.3 \%$ relative to the counterfactual. But these long-run consumption gains are heavily discounted in the welfare computation. Experiments with the model show that implementing a linear transition path for the income shares (while preserving the endpoints) improves the welfare outcomes for both types of agents; capital owners now achieve a gain of $4.8 \%$ while the loss for workers is smaller at $0.35 \%$. This result highlights the importance of accurately modeling the historical paths of the U.S. income shares. In contrast, shutting off the model productivity shocks has only a minor effect on the welfare outcomes.

An important unsettled issue in the literature is the degree to which rising U.S. income

Nominal transfer payments to individuals are from FRED and are deflated by the NIPA price index for personal consumption expenditures. Real output is defined as the sum of real consumption, real private investment and real government consumption and investment. Population data are from NIPA Table 2.1, line 40. 
inequality has translated into rising consumption inequality. Empirical studies by Krueger and Perri (2006) and Meyer and Sullivan (2013) find that the rise in U.S. consumption inequality has been less-pronounced than the rise in income inequality. Aguiar and Bils (2015) and Attanasio, et al. (2012) argue that consumption inequality, when measured in a different manner, appears to closely track income inequality. In our baseline simulation, the consumption share of the top quintile (capital owners) rises more gradually than their pre-tax income share. Specifically, the consumption share of capital owners rises by less than 3 percentage points while their pre-tax income share rises by 8 percentage points. We show that the model's prediction for the capital owners' consumption share tracks reasonably well with data on the consumption share of high income households (80th through 95th percentiles) from the Consumer Expenditure Survey (CES) over the period 1980 to 2010.

We also examine the model's prediction for the behavior of real equity values over the period 1970 to 2013. Not surprisingly, the market value of the S\&P 500 is far more volatile than the model equity value. Nevertheless, the correlation coefficient between changes in the $\mathrm{S} \& \mathrm{P} 500$ market value and changes in the model equity value is 0.25 . This result is consistent with recent research which finds that "factor share shocks" are an important driver of U.S. stock market fluctuations (Greenwald, Lettau, and Ludvigson 2014, Lansing 2015).

As part of our sensitivity analysis, we consider how different categories of income contribute to the welfare effects of the transition. All else equal, when capital's share of total income is held constant at its 1970 value of $35 \%$ (rather than increasing to 44\%), capital owners suffer a welfare loss of $0.34 \%$ while workers enjoy a welfare gain of $5.8 \%$. When the ratio of redistributive transfers to output is held constant at its 1970 value of $7.4 \%$ (rather than increasing to $14.6 \%$ ), workers suffer a large welfare loss of $10.7 \%$ versus a loss of $1.4 \%$ in the baseline simulation. This result suggests that the historical pattern of U.S. transfer payments has been very effective in mitigating the negative impacts of rising income inequality.

As a supplement to the positive analysis summarized above, we undertake two normative experiments. Taking the paths of the U.S. pre-tax income shares as given, we solve for the optimal time series of redistributive transfers that equalizes agents' marginal utility of consumption each period from 1971 onwards. We assume that the social planner finances the new level of transfers and other government spending by adjusting the path of the income tax rate relative to the baseline simulation, but with other relevant variables equal to those in the baseline simulation. We find that the optimal transfer-output ratio must rise to around $37 \%$ by the year 2013. Relative to the counterfactual scenario (no change in income shares or the transfer-output ratio), capital owners suffer a welfare loss of $36.8 \%$ while workers enjoy a gain of $17 \%$.

As a more realistic normative experiment, we compute a Pareto-improving time series of 
transfers that delivers equal welfare gains to capital owners and workers over the simulation. In this case, the transfer-output ratio must rise to around $18 \%$ percent by the year 2013 somewhat higher than the actual value of $14.6 \%$ observed in the data. The welfare gain for both types of agents turns out to be rather small-only $0.28 \%$ of per-period consumption. This is due to the need for a higher tax rate path to finance the higher level of transfers. Still, the experiment suggests that realistic policy actions could be effective in mitigating the negative impacts of rising income inequality.

\section{$1.1 \quad$ Related Literature}

Our analysis examines the consequences of rising inequality that is driven by gains in top incomes, defined here as the highest $20 \%$ of earners. In contrast, the vast majority of previous research has focused on inequality that is driven by the rising wage premium of college-educated workers. ${ }^{10}$ Our framework takes into account the simultaneous shifts in the distribution of both labor and capital incomes in U.S. data. According to Alvaredo, et al. (2013), the increased correlation between top labor incomes and top capital incomes is an important but often-overlooked factor contributing to the rise in U.S. income inequality.

As an alternative to technological explanations for rising income inequality (such as shifting production functions), Piketty, Saez, and Stantcheva (2014) argue that the dramatic rise in top incomes has been driven mainly by institutional changes which strengthened the bargaining power of top earners at the expense of lower earners. According to this "grabbing hand" theory, the shift in bargaining power has enabled rent-seeking top earners to successfully push their pay above their marginal product. While the grabbing-hand theory may have different implications for social welfare, the welfare consequences for each class of agents would still be linked to the resulting paths for their income and consumption, which our quantitative analysis explicitly takes into account. Kumhof, Rancière, and Winantet (2015) consider an endowment economy where rising income inequality (as measured by the income share of the top $5 \%$ of households) is driven by a exogenous stochastic process with a unit root. They do not consider welfare but instead focus on the links between rising inequality, increased household leverage, and the risk of a financial crisis.

\section{Model}

The model consists of workers, capital owners, competitive firms, and the government. There are $n$ times more workers than capital owners, with the total number of capital owners normal-

\footnotetext{
${ }^{10}$ See, for example, Attanasio and Davis (1996), Krussell, et al. (2000), Goldin and Katz (2007, 2008) and Heathcote, Storesletten, and Violante (2010, 2011).
} 
ized to one. Naturally, the firms are owned by the capital owners. Workers and capital owners both supply labor to the firms inelastically, but in different amounts. ${ }^{11}$ The government levies distortionary taxes on both types of agents to finance public consumption expenditures and redistributive transfers.

\section{$2.1 \quad$ Workers}

The individual worker's decision problem is to maximize

$$
E_{0} \sum_{t=0}^{\infty} \beta^{t} \log \left(c_{t}^{w}\right),
$$

subject to the budget constraint

$$
c_{t}^{w}=\left(1-\tau_{t}\right) w_{t}^{w} \ell_{t}^{w}+T_{t} / n,
$$

where $E_{t}$ represents the mathematical expectation operator, $\beta$ is the subjective time discount factor, $c_{t}^{w}$ is the individual worker's consumption, $w_{t}^{w}$ is the worker's competitive market wage, $\ell_{t}^{w}=\ell^{w}$ is the constant supply of labor hours per worker, and $\tau_{t}$ is the income tax rate. Workers are assumed to incur a transaction cost for saving or borrowing small amounts which prohibits their participation in financial markets. As a result, they simply consume their resources each period, consisting of after-tax labor income $w_{t}^{w} \ell_{t}^{w}\left(1-\tau_{t}\right)$ and a per-worker transfer payment $T_{t} / n$ received from the government.

\subsection{Capital Owners}

Capital owners represent the top quintile of earners. Their decision problem is to maximize

$$
E_{0} \sum_{t=0}^{\infty} \beta^{t} \log \left(c_{t}^{c}\right),
$$

subject to the budget constraint

$$
c_{t}^{c}+i_{t}=w_{t}^{c} \ell_{t}^{c}+r_{t} k_{t}-\tau_{t}\left(w_{t}^{c} \ell_{t}^{c}+r_{t} k_{t}-\phi_{t} i_{t}\right)
$$

where $c_{t}^{c}$ is the individual capital owner's consumption and $\ell_{t}^{c}=\ell^{c}$ is the constant supply of labor hours. The symbol $i_{t}$ represents investment in physical capital $k_{t}$. For simplicity, we assume that the functional form of the utility function, the discount factor $\beta$, and the income tax rate $\tau_{t}$ are the same for both capital owners and workers. Capital owners derive income by supplying labor and capital services to firms. They earn a wage $w_{t}^{c}$ for each unit of labor

\footnotetext{
${ }^{11}$ The model setup is similar to a standard framework that is often used to study optimal redistributive capital taxation. See, for example, Judd (1985), Lansing (1999), and Krusell (2002). In these examples, however, capital owners do not supply labor.
} 
employed by the firm and receive the rental rate $r_{t}$ for each unit of physical capital used in production.

Taxable income in equation (4) is given by the expression in parentheses. Following Cassou and Lansing (2006), we allow for differential tax treatment of labor and capital incomes via the wedge $\phi_{t} \in[0,1]$ which represents the fraction of investment that can be "expensed," or immediately deducted from taxable income. For comparison with the U.S. tax system, $\phi_{t}$ can be interpreted as an index number that summarizes the various elements of the tax code that encourage saving or investment. These elements include the depreciation allowance for physical capital, the tax-deferred status of saving done through pensions, 401(k)s or IRAs, and the favorable tax treatment of long-term capital gains. When $\phi_{t}=1$, capital owners are subjected to a pure consumption tax..$^{12}$

Resources devoted to investment augment the stock of physical capital according to the law of motion

$$
k_{t+1}=B k_{t}^{1-\lambda} i_{t}^{\lambda}
$$

with $k_{0}$ given. The parameter $\lambda \in(0,1]$ is the elasticity of new capital with respect to new investment. When $\lambda<1$, equation (5) reflects the presence of capital adjustment costs. ${ }^{13} \mathrm{We}$ use the capital law of motion to eliminate $i_{t}$ from the budget constraint (4).

The capital owner's first-order condition with respect to $k_{t+1}$ is given by

$$
\underbrace{\frac{\left(1-\phi_{t} \tau_{t}\right) i_{t}}{\lambda}}_{p_{t}}=E_{t} M_{t+1}^{c}[\underbrace{\left(1-\tau_{t+1}\right) r_{t+1} k_{t+1}-\left(1-\phi_{t+1} \tau_{t+1}\right) i_{t+1}}_{d_{t+1}}+\underbrace{\frac{\left(1-\phi_{t} \tau_{t}\right) i_{t}}{\lambda}}_{p_{t+1}}],
$$

where $M_{t+1}^{c} \equiv \beta\left(c_{t+1}^{c} / c_{t}^{c}\right)^{-1}$ is the capital owner's stochastic discount factor. ${ }^{14}$ The first-order condition takes the form of a standard asset pricing equation where $p_{t}=\left(1-\phi_{t} \tau_{t}\right) i_{t} / \lambda$ is the market value of the capital owner's equity shares in the firm. These equity shares entitle the capital owner to a perpetual stream of dividends $d_{t+1}$ starting in period $t+1$. The model's adjustment cost specification (5) implies a direct link between equity values and investment. This feature is consistent with the observed low-frequency comovement between the real S\&P 500 stock market index and real business investment in recent decades, as documented by Lansing (2012).

\footnotetext{
${ }^{12}$ When $\phi_{t}=1$, the capital owner's budget constraint can be rewritten as: $\left(1+\tau_{c, t}\right) c_{t}+i_{t}=w_{t}^{c} \ell_{t}^{c}+r_{t} k_{t}$, where $\tau_{c, t}$ is the consumption tax rate given by $\tau_{c, t}=\tau_{t} /\left(1-\tau_{t}\right)$.

${ }^{13}$ Since equation (5) can be written as $k_{t+1} / k_{t}=B\left(i_{t} / k_{t}\right)^{\lambda}$, our adjustment cost specification can be viewed as a log-linearized version of the following law of motion employed by Jermann $(1998): k_{t+1} / k_{t}=$ $1-\delta+\psi_{0}\left(i_{t} / k_{t}\right)^{\psi_{1}}$. For details, see Lansing (2012), p. 467.

${ }^{14}$ After taking the derivitive of the capital owner's Lagrangian with respect to $k_{t+1}$, we have multiplied both sides of the resulting expression by the ratio $k_{t+1} / c_{t}^{c}$ which is known at time $t$.
} 


\section{$2.3 \quad$ Firms}

Identical competitive firms are owned by the capital owners and produce output according to the technology

$$
\begin{aligned}
& y_{t}=A k_{t}^{\theta_{t}}\left[\exp \left(z_{t}\right)\left(\ell_{t}^{c}\right)^{\alpha_{t}}\left(n \ell_{t}^{w}\right)^{1-\alpha_{t}}\right]^{1-\theta_{t}}, \quad A>0, \\
& z_{t}=z_{t-1}+\mu+\varepsilon_{t}, \quad \varepsilon_{t} \sim N I D\left(0, \sigma_{\varepsilon}^{2}\right) \\
& s_{t} \equiv \frac{\theta_{t}}{\theta_{t}+\alpha_{t}\left(1-\theta_{t}\right)}, \\
& s_{t}=\left(s_{t-1}\right)^{\rho}(\widetilde{s})^{1-\rho} \exp \left(u_{t}\right), \quad \begin{array}{l}
\widetilde{s} \equiv \exp \left\{E\left[\log \left(s_{t}\right)\right]\right\}, \quad \mid<1, \quad u_{t} \sim N I D\left(0, \sigma_{u}^{2}\right),
\end{array}
\end{aligned}
$$

with $z_{0}$ and $s_{0}$ given. In equation $(7), z_{t}$ represents a labor-augmenting "productivity shock" that evolves as a random walk with drift. The drift parameter $\mu$ determines the trend growth rate of the economy. The shock innovation $\varepsilon_{t}$ is normally and independently distributed $(N I D)$ with mean zero and variance $\sigma_{\varepsilon}^{2}$. Stochastic shifts in the the production function exponents $\theta_{t}$ and $\alpha_{t}$ represent "distribution shocks" along the lines of Young (2004), Ríos-Rull and Santaeulàlia-Llopis (2010), and Lansing (2015). Given the Cobb-Douglas form of the production function, $\theta_{t}$ is capital's share of income, $\theta_{t}+\alpha_{t}\left(1-\theta_{t}\right)$ is the top quintile income share, $\alpha_{t}\left(1-\theta_{t}\right)$ is the labor income share of the capital owners, and $\left(1-\alpha_{t}\right)\left(1-\theta_{t}\right)$ is the income share of the workers, representing the bottom four quintiles.

Recall from Figure 1 that the U.S. income shares exhibit sustained upward trends over the period 1970 to 2013. To facilitate a solution of the model in terms of stationary variables, we define the variable $s_{t}$ as the ratio of capital's share of income to the top quintile income share. Figure 3 shows that the empirical counterpart of $s_{t}$ in U.S. data appears to be stationary but persistent. To capture this feature of the data, we postulate that $s_{t}$ in the model evolves according to the law of motion (10) with persistence parameter $\rho$ and innovation variance $\sigma_{u}^{2}$.

Profit maximization by firms yields the following factor prices

$$
\begin{aligned}
r_{t} & =\frac{\theta_{t} y_{t}}{k_{t}}, \\
w_{t}^{c} & =\frac{\alpha_{t}\left(1-\theta_{t}\right) y_{t}}{\ell^{c}}, \\
w_{t}^{w} & =\frac{\left(1-\alpha_{t}\right)\left(1-\theta_{t}\right) y_{t}}{n \ell^{w}},
\end{aligned}
$$

which reflect the constant labor supplies $\ell^{c}$ and $\ell^{w}$. 


\subsection{Government}

The government collects tax revenue from capital owners and workers in order to finance expenditures on public consumption and redistributive transfers. We assume that the government's budget constraint is balanced each period, as given by

$$
g_{t}+T_{t}=\tau_{t}[\underbrace{n w_{t}^{w} \ell^{w}+w_{t}^{c} \ell^{c}+r_{t} k_{t}}_{y_{t}}-\phi_{t} i_{t}]
$$

where $g_{t}$ is public consumption and $T_{t}$ is aggregate redistributive transfers. The balancedbudget constraint can be viewed as an approximation to the consolidated budgets of federal, state, and local governments. Public consumption does not provide direct utility to either capital owners or workers. Nevertheless, we include $g_{t}$ in our analysis to obtain quantitatively realistic tax rates during the transition period from 1970 to 2013.

\subsection{Decision Rules and Computation}

Given that labor supply is inelastic, workers simply consume their after-tax income plus transfers each period according to their budget constraint (2). In equilibrium, the individual worker's consumption is given by

$$
c_{t}^{w}=\left(1-\tau_{t}\right)\left(1-\alpha_{t}\right)\left(1-\theta_{t}\right) y_{t} / n+T_{t} / n
$$

where we have substituted in the worker's equilibrium real wage (13).

Capital owners must only decide the fraction of their after-tax income to be devoted to investment, with the remaining fraction devoted to consumption. As shown in Appendix A, the capital owner's optimization problem can be formulated in terms of a single decision variable, namely, the tax-adjusted investment-consumption ratio given by $x_{t} \equiv\left(1-\phi_{t} \tau_{t}\right) i_{t} / c_{t}^{c}$, Our choice of functional forms (log utility and Cobb-Douglas forms for production and the capital law of motion) delivers a simple approximate decision rule for $x_{t}$ in terms of the state variable $s_{t}$, where $s_{t}$ evolves according to the law of motion (10). In Appendix A we show that $x_{t}$ is increasing in $\theta_{t}$. Hence, an increase in capital's share of income causes the capital owner to devote more resources to investment rather than consumption.

Given the decision rule $x_{t}=x\left(s_{t}\right)$, the equilibrium version of the capital owner's budget constraint (4) can be used to derive the following expressions for the capital owner's allocations:

$$
\begin{aligned}
c_{t}^{c} & =\frac{1}{1+x\left(s_{t}\right)}\left(1-\tau_{t}\right)\left[\theta_{t}+\alpha_{t}\left(1-\theta_{t}\right)\right] y_{t}, \\
i_{t} & =\frac{x\left(s_{t}\right)}{1+x\left(s_{t}\right)}\left(\frac{1-\tau_{t}}{1-\phi_{t} \tau}\right)\left[\theta_{t}+\alpha_{t}\left(1-\theta_{t}\right)\right] y_{t} .
\end{aligned}
$$


A convenient property of our setup is that we do not need to specify the laws of motion for the tax wedges $\tau_{t}$ and $\phi_{t}$ in order to solve for the capital owner's allocations. ${ }^{15}$ In our quantitative analysis, we treat the tax wedges as unobservable and solve for time series of $\tau_{t}$ and $\phi_{t}$ that allow the model to exactly replicate the observed time paths of the four U.S. macroeconomic ratios plotted in Figure 2. Simultaneously, we solve for a time series of productivity shocks $z_{t}$ that cause the model to exactly replicate the denominator of the U.S. macroeconomic ratios, i.e., real per capita output over the period 1970 to 2013, where the level of real output in 1970 is normalized to 1.0. The time series for the state variable $s_{t}$ is taken directly from U.S. data, as plotted in Figure 3. Afterwards, we use the laws of motion for the shocks (8) and (10) to recover the time series of innovations $\varepsilon_{t}$ and $u_{t}$. For periods beyond 2013, we assume that all shock innovations are zero, while income shares, tax wedges, and the various macroeconomic ratios remain constant at year 2013 values. Further details regarding our simulation procedure are contained in Appendix B.

\section{Model Calibration}

Table 1 summarizes our choice of parameter values for the baseline simulation. Parameters values are set to achieve target values for observed U.S. variables within the sample period of 1970 to 2013.

Table 1: Baseline Parameter Values

\begin{tabular}{ccl}
\hline \hline Parameter & Value & \\
\hline$n$ & 4 & Capital owners $=$ top income quintile. \\
$\theta_{0}$ & 0.3500 & Capital's share of income $=0.350$ in 1970. \\
$\alpha_{0}$ & 0.1277 & Top quintile income share $=0.433$ in 1970. \\
$\tau_{0}$ & 0.3913 & $g_{t} / y_{t}+T_{t} / y_{t}=0.383$ in 1970. \\
$\phi_{0}$ & 0.28446 & $i_{t} / y_{t}=0.075$ in 1970. \\
$\ell^{c} / \ell^{w}$ & 0.2928 & Mean relative wage $w^{c} / w^{w}=2$ in 1970. \\
$\mu$ & 0.0200 & Mean per capita consumption growth $=2 \%, 1970$ to 2013. \\
$\beta$ & 0.9681 & Mean log equity return $=5.25 \%, 1970$ to 2013. \\
$A$ & 0.5176 & $y_{t}=1$ in 1970. \\
$B$ & 1.0599 & Mean $i_{t} / k_{t}=0.08$. \\
$\lambda$ & 0.0151 & $\widetilde{x} \equiv \exp \left\{E\left[\log \left(x_{t}\right)\right]\right\}=0.3350,1970$ to 2013. \\
$\widetilde{s}$ & 0.7985 & $\widetilde{s} \equiv \exp \left\{E\left[\log \left(s_{t}\right)\right]\right\}=0.7985,1970$ to 2013. \\
$\rho$ & 0.8584 & Corr. $\left[\log \left(s_{t}\right), \log \left(s_{t-1}\right)\right]=0.8584,1970$ to 2013. \\
$\sigma_{u}$ & 0.0255 & Std. dev. $\log \left(s_{t}\right)=0.0496,1970$ to 2013. \\
$\sigma_{\varepsilon}$ & 0.0404 & Std. dev. per capita output growth $=1.7 \%, 1970$ to 2013. \\
\hline
\end{tabular}

The time period in the model is one year. The number of workers per capital owner is $n=4$ so that capital owners represent the top quintile of earners. In the model, capital owners

\footnotetext{
${ }^{15}$ This is because the income and substitution effects of changes in $\tau_{t}$ or $\phi_{t}$ are offsetting.
} 
possess $100 \%$ of the physical capital wealth - a reasonable approximation to the U.S. financial wealth distribution in which the ownership share of the top quintile of earners is around $92 \% .{ }^{16}$

The initial capital income share $\theta_{0}$ is set to match the 1970 observed value of 0.35 , as shown in the bottom right panel of Figure 1. The initial production elasticity of the capital owner's labor supply $\alpha_{0}$ is set to achieve an initial top quintile income share of $\theta_{0}+\left(1-\theta_{0}\right) \alpha_{0}=0.433$, corresponding to 1970 observed value as shown in the top right panel of Figure 1. Given these values, the labor supply ratio $\ell^{c} / \ell^{w}$ is set so that the initial wage ratio in 1970 is $w^{c} / w^{w}=2$ with $\ell^{w}$ normalized to 1. For comparison, Heathcote, Storesletten, and Violante (2010), p. 686 report a male college wage premium of about 1.5 in 1970, whereas Gottschalk and Danziger (2005), p. 238 report a male wage ratio of 4.1 in 1979 when comparing the top decile to the bottom decile. The wage ratio $w^{c} / w^{w}$ in our model compares the top quintile to the remainder of households, so one would expect it to fall somewhere in between the values reported by the two studies, but likely closer to the value reported by Heathcote, Storesletten, and Violante (2010). The quantitative results exhibit little sensitivity to the value of the initial wage ratio.

The value $\mu=0.02$ matches the average growth rate of real per capita aggregate consumption over the period 1970 to 2013 . Given $\mu$, we choose $\beta$ to achieve a mean log equity return of $5.25 \%$, coinciding with the corresponding real return delivered by the S\&P 500 stock index over the period 1970 to $2013 .^{17}$

The level of real per capita output in the U.S. data is normalized to 1.0 in the year 1970 . We calibrate the value of $A$ in the production function (7) to yield $y_{t}=1$ at $t_{0}=1970$. The calibration assumes $k_{t} / y_{t}=0.93$ in 1970 which is obtained by combining the observed U.S. value of $i_{t} / y_{t}=0.075$ in 1970 with a typical long-run value for the investment-capital ratio $i_{t} / k_{t}$. For example, in a model with no capital adjustment costs, we have $i_{t} / k_{t}=k_{t+1} / k_{t}+1-\delta$, where $\delta$ is the annual depreciation rate of physical capital. For the calibration, we employ the value $\delta=0.06$ which in turn yields the long-run value $i_{t} / k_{t}=\exp (0.02)+1-0.06=0.08$. Given the calibrated value for $\lambda$ (described below), we set the parameter $B$ in the capital law of motion (5) such that $B=\left(k_{t+1} / k_{t}\right)\left(i_{t} / k_{t}\right)^{-\lambda}$, where $k_{t+1} / k_{t}=\exp (0.02)$ and $i_{t} / k_{t}=0.08$.

The parameter $\lambda$ governs the strength of capital adjustment costs and depreciation. The value of $\lambda$ influences the coefficients in the capital owner's decision rule $x_{t}=x\left(s_{t}\right)$, where $x_{t} \equiv$ $\left(1-\phi_{t} \tau_{t}\right) i_{t} / c_{t}^{c}$. We choose the value of $\lambda$ to a achieve the target value $\widetilde{x} \equiv \exp \left\{E\left[\log \left(x_{t}\right)\right]\right\}=$ 0.3287. This target value is computed using the 1970 to 2013 average values of the U.S. macroeconomic ratios plotted in Figure 2. Details of the calibration procedure for $\lambda$ are contained in Appendix A.

\footnotetext{
${ }^{16}$ See Wolff (2010), Table 2, p. 44.

${ }^{17}$ The mean $\log$ equity return in the model is given by $E\left[\log \left(R_{t+1}^{s}\right)\right]=-\log (\beta)+\mu$. Data on real log equity returns for the S\&P 500 stock index are from Robert Shiller's website.
} 
Recall that $s_{t}$ represents the ratio of capital's share of income to the top quintile income share (Figure 3). We choose the parameters $\widetilde{s}, \rho$, and $\sigma_{u}$ in the law of motion (10) to match the mean, persistence, and volatility of $\log \left(s_{t}\right)$ in U.S. data over the period 1970 to 2013.

Given values for $\lambda, \widetilde{x}$, and $\widetilde{s}$, and the capital owner's decision rules for $x_{t}$ and $i_{t}$, we solve $\phi_{0}$ and $\tau_{0}$ such that the model delivers the observed values $i_{t} / y_{t}=0.075$ and $g_{t} / y_{t}+T_{t} / y_{t}=0.383$ at $t_{0}=1970$. A similar procedure is used to solve for $\phi_{t}$ and $\tau_{t}$ for each $t>t_{0}$, as described in Appendix B.

After computing the time series of productivity shocks $z_{t}$ that cause the model to exactly replicate the path of U.S. real per capita output, we use the law of motion (8) to recover the implied sequence of innovations $\varepsilon_{t}$, with $z_{t}=0$ at $t_{0}=1970$. The standard deviation of the implied shock innovations turns out to be $\sigma_{\varepsilon}=0.0404$. The corresponding standard deviation of output growth in both the model and the data is $1.7 \%$ over the period 1970 to 2013.

\section{Intuition for the Results}

Before moving to the quantitative analysis, this section inspects the basic mechanism that determines how a shifting income share affects capital owners versus workers. Consider a stripped-down version of the model with no labor supply for capital owners $\left(\alpha_{t}=0\right)$, unit labor supply for workers $\left(\ell^{w}=1\right)$, no growth $\left(z_{t}=0\right)$, an equal number of capital owners and workers $(n=1)$, no taxes $\left(\tau_{t}=0\right)$, and no capital adjustment costs such that $k_{t+1}=$ $(1-\delta) k_{t}+i_{t}$, where $\delta$ is the capital depreciation rate. Output is given by $y_{t}=A k_{t}^{\theta_{t}}$. The incomes of the capital owners and workers are $\theta_{t} y_{t}$ and $\left(1-\theta_{t}\right) y_{t}$, respectively.

In response to a one-time increase in $\theta_{t}$, the capital stock cannot respond immediately so the short-run response of output is muted relative to the long-run response. In the short-run, the income of capital owners will rise while the income of workers will fall. These shortrun effects will have a large influence on welfare because they are not discounted much in calculating lifetime utility.

But the increase in $\theta_{t}$ will also stimulate an increase in $i_{t}$, thus raising $k_{t+1}$ and $y_{t+1} \cdot{ }^{18} \mathrm{As}$ time goes by, the income of workers will be boosted by the rising level of output. In steady state, (i.e., the very long-run), output is given by

$$
y=A^{\frac{1}{1-\theta}}\left[\frac{\beta \theta}{1-\beta(1-\delta)}\right]^{\frac{\theta}{1-\theta}}
$$

which shows that an increase in $\theta$ leads to an increase in $y$. It is straightforward to show that for reasonable parameterizations, an increase in $\theta$ also leads to an increase in $(1-\theta) y$. In other words, an increase in capital's share of income will also boost the long-run level of

\footnotetext{
${ }^{18}$ The closed-form investment decision rule for capital owners is $i_{t}=\beta \theta_{t} y_{t}-(1-\beta)(1-\delta) k_{t}$.
} 
income for workers. But since this takes place in the very long-run, the influence on welfare is small due to discounting.

While an increase in $\theta$ unambiguously benefits the welfare of capital owners, the welfare impact on workers will depend on how fast capital and output converge to the new steady state. Short-term losses must be balanced against long-term gains. ${ }^{19}$ In the quantitative analysis that follows, we examine both the short-run and long-run effects of rising income inequality in a realistic model that matches numerous features of the U.S. data.

\section{Quantitative Analysis}

We first consider a baseline simulation that exactly replicates the observed U.S. time paths of the top quintile income share, capital's share of income, and key macroeconomic variables over the period 1970 to 2013. The baseline simulation is compared to a counterfactual scenario in which income shares and the transfer-output ratio do not change.

As an independent check on the validity of our framework, we compare the model prediction for the path of the top quintile consumption share to data from the Consumer Expenditure Survey. We also compare the model's prediction for real equity values to movements in the S\&P 500. We then undertake two normative experiments that alter the time series of redistributive transfers and income tax rates relative to those in the baseline simulation.

\subsection{Baseline Simulation vs. Counterfactual Scenario}

Figure 4 plots the simulated trajectories of four model variables: output $y_{t}$, investment $i_{t}$, the capital owner's consumption $c_{t}^{c}$, and the worker's consumption $c_{t}^{w}$. For each variable, we compare the baseline simulation to a counterfactual scenario in which the income share variables $\theta_{t}$ and $\alpha_{t}$ and the transfer-output ratio $T_{t} / y_{t}$ are held constant at $t_{0}=1970$ values. Both scenarios employ the same time series for $\tau_{t}, \phi_{t}$, and $z_{t}$ to isolate the effects of rising income shares and transfers, as opposed to changes in tax policy or changes in the business cycle. ${ }^{20}$ By holding $T_{t} / y_{t}$ constant in the counterfactual scenario, we adopt the view that the upward trend of $T_{t} / y_{t}$ observed in the data was a deliberate government policy response to the trend of rising pre-tax income inequality. In other words, an upward trend in $T_{t} / y_{t}$ would not have been necessary if pre-tax income inequality had remained low. ${ }^{21}$ Later, in the welfare

\footnotetext{
${ }^{19}$ We thank an anonymous referee for suggesting this simple intuition.

${ }^{20}$ For the counterfactual scenario, government expenditures $g_{t}$ serve as the residual component of spending to absorb any differences in collected tax revenue and transfers relative to the baseline scenario. Specifically, we have $g_{t}=\tau_{t}\left(y_{t}-\phi_{t} i_{t}\right)-y_{t}\left(T_{0} / y_{0}\right)$, where $T_{0} / y_{0}=0.074$ in the year 1970 .

${ }^{21}$ Figure 2 shows that $T_{t} / y$ in the data rose from $7.4 \%$ in 1970 to $11.8 \%$ in 2005 . It remained approximately constant at around $12 \%$ through 2007 . Then, over the next three years, the ratio increased rapidly, peaking at $15.3 \%$ in 2010 . The ratio has since come down a bit to $14.6 \%$ at the end of our data sample in 2013. While
} 
analysis, we will consider an alternative counterfactual simulation in which we allow for rising income shares (as in the data), but hold $T_{t} / y_{t}$ constant.

The top left panel of Figure 4 shows that output in the baseline simulation falls below the counterfactual path over most of the sample period from 1970 to 2013. The average annual growth rate of $y_{t}$ over the 44 -year period is $1.78 \%$ in the baseline simulation versus $2.00 \%$ in the counterfactual. This result can be traced to the increase in capital's share of income $\theta_{t}$ under the baseline simulation which shrinks the output contribution coming from the model's growth engine, namely, labor-augmenting technological progress as given by $\exp \left[\left(1-\theta_{t}\right) z_{t}\right]$. The slowdown in output growth is consistent with the narratives emphasized by Hornstein and Krusell (1996) and Greenwood and Yörükoğlu (1997) whereby a biased technology change initially leads to a measured slowdown in total factor productivity.

It takes a long time for the model transition dynamics to fully play out. The increase in the marginal product of capital, as measured by $\theta_{t}$, stimulates an increase in investment $i_{t}$ relative to the counterfactual scenario (top right panel of Figure 4). Once $\theta_{t}$ stops increasing, the higher level of investment in the baseline simulation causes the level of output to eventually catch up and surpass the counterfactual output path around the year 2150, well beyond the time scale plotted in Figure 4. After all of the model transition dynamics have played out, the baseline simulation delivers the same growth rate as the counterfactual scenario, but there is permanent upward shift in the level of output equal to $4.3 \%$. The permanent level shift derives from the unit root in the law of motion for $z_{t}$.

The lower two panels in Figure 4 show the paths of the capital owner's consumption $c_{t}^{c}$ and the worker's consumption $c_{t}^{w}$. Relative to the counterfactual scenario, consumption growth for capital owners exhibits a higher mean $(2.2 \%$ versus $2.0 \%)$ and a lower volatility $(2.8 \%$ versus $3.3 \%$ ) from 1970 to 2013. Beyond 2013, the capital owner's consumption pulls further away from the counterfactual path. In the long-run (i.e., at the end of a 3000 period simulation), the capital owner's consumption experiences a permanent upward level shift of $22.4 \%$ relative to the counterfactual path.

The worker's consumption (lower right panel of Figure 4) falls below the counterfactual path during a substantial portion of the transition period from 1970 to 2013 . But after 44 years, the level of the worker's consumption is about the same under both scenarios. The volatility of the worker's consumption growth is substantially lower in the baseline simulation $(1.8 \%$ versus $3.2 \%$ ). The lower volatility stems from the countercyclical behavior of government redistributive transfers. In the baseline simulation (and in the U.S. data), the correlation

some of the run-up in $T_{t} / y_{t}$ in recent years appears to have been triggered by the government's response to the financial crisis of 2007-09, it is also true that the top quintile income share continued to trend upward over this same period. Moreover, the value of $T_{t} / y_{t}$ in 2013 is only slightly below the peak value achieved in 2010 , suggesting that much of the recent run-up may be permanent rather than temporary. 
coefficient between the growth rate of real transfer payments and the growth rate of real output is -0.47 over the period 1970 to 2013 . The consumption-smoothing effect of these transfers is taken into account by our welfare analysis, as described further below. Beyond 2013, the worker's consumption eventually catches up to the counterfactual path around the year 2040. The catch-up is driven by the higher level of investment in the baseline simulation which contributes to more capital accumulation and more output per worker in the long-run. More output per workers implies more transfers per worker because $T_{t} / y_{t}=0.146$ for all $t \geq 2013$. At the end of the 3000 period simulation, the worker's consumption experiences a permanent upward level shift of $10.3 \%$ relative to the counterfactual.

Figure 5 plots the time series of the two tax wedge innovations $\left(\Delta \tau_{t}\right.$ and $\left.\Delta \phi_{t}\right)$ and the two stochastic shock innovations $\left(\varepsilon_{t}\right.$ and $u_{t}$ ) that are needed to make the baseline simulation exactly replicate the paths of U.S. macroeconomic variables over the period 1970 to 2013. By construction, the innovations are zero at $t_{0}=1970$ and for all $t>2013$. The mean values of $\Delta \tau_{t}, \varepsilon_{t}$ and $u_{t}$ are close to zero over the period 1970 to 2013 while the mean value of the $\Delta \phi_{t}$ is positive at 0.016 . The resulting net increase in the investment expensing fraction $\phi_{t}$ allows the model to replicate the rising ratio of U.S. nonresidential private investment to output (Figure 2). In the lower left panel of Figure 5, the identified productivity shock innovation $\varepsilon_{t}$ is negative during the U.S. recession years of 1974-75, 1980-82, 1990-91, and 2008-09. ${ }^{22}$

Figure 6 plots the ratios of macroeconomic variables to output generated by the model. In the top two panels, the baseline simulation exactly replicates the 1970 to 2013 observed U.S. time paths for the ratios $c_{t} / y_{t}$ and $i_{t} / y_{t}$, as plotted earlier in Figure $2 .{ }^{23}$ We use the model decision rules to construct paths for $c_{t}^{c} / y_{t}$, and $c_{t}^{w} / y_{t}$ which, when aggregated, are consistent with the evolution of the ratio $c_{t} / y_{t}$ in the U.S. data.

In the baseline simulation, the capital owner's consumption increases faster than output such that $c_{t}^{c} / y_{t}$ goes from $20 \%$ in 1970 to nearly $24 \%$ in 2013 (bottom left panel of Figure 6). In contrast, $c_{t}^{w} / y_{t}$ increases only slightly from $10.5 \%$ in 1970 to $11.3 \%$ in 2013 (bottom right panel of Figure 6). The small increase in $c_{t}^{w} / y_{t}$ is due to the rising transfer-output ratio in the baseline simulation which offsets the workers' shrinking income share. In the absence of a rising transfer-output ratio, the worker's consumption ratio would drop to $9.4 \%$ by 2013 . In the counterfactual scenario, the worker's consumption ratio fluctuates in response to changes in tax wedges and productivity shocks, but the ratio experiences little net change after 44 years.

\footnotetext{
${ }^{22}$ The U.S. recession years are from http://www.nber.org/cycles.html.

${ }^{23}$ Although not shown, the baseline simulation also replicates the observed U.S. time paths for the ratios $g_{t} / y_{t}$ and $T_{t} / y_{t}$.
} 


\subsection{Model vs. Data: Income and Consumption Inequality}

Figure 7 shows that the rise in consumption inequality in the model is less-pronounced than the rise in income inequality. This is true regardless of whether income is measured before or after taxes and transfers. The model's top quintile income share before taxes (solid blue line) exactly replicates the U.S. Census Bureau data plotted earlier in the top right panel of Figure 1. The pre-tax income share rises by 8 percentage points (from $43 \%$ to $51 \%$ ) while the aftertax income share (dashed red line) increases by about 5 percentage points. In contrast, the consumption share of the top quintile (dashed-dot green line) rises by less than 3 percentage points (from $32 \%$ to $34.4 \%$ ). The smaller rise in consumption inequality in the model is due to two factors: (1) the rising investment-output ratio (replicating U.S. data) which is financed entirely by more saving from capital owners, and (2) the rising transfer-output ratio which helps to mitigate the workers' shrinking income share.

For comparison, Figure 7 plots the consumption share of high-income households (those in the 80th through 95th percentiles) using data from the Consumer Expenditure Survey (CES) for the period 1980 and 2010. The consumption of high-income households is computed using two methods: (1) reported after-tax income minus saving, and (2) reported expenditures. The consumption share from the first method is noticeably higher than that from the second method. This gap is similarly evident in the data reported by Aguiar and Bils (2011), Table 1, p. 30. A later version of the same paper (Aguiar and Bils, 2015) highlights the growing discrepancy between the CES expenditure data and the aggregate consumption data from the National Income and Product Accounts (NIPA). This discrepancy affects the comparison in Figure 7 because our model exactly replicates the path of the NIPA aggregate consumption data from 1970 to $2013 .^{24}$

Notwithstanding the data issues noted above, the model's prediction for the capital owners' consumption share tracks reasonably well with the consumption share of high-income households computed from the CES data (grey lines). From 1980 to 2010, the net increase in the CES consumption share is 3.1 percentage points using the income minus saving data and 1.9 percentage points using the reported expenditure data. Over the same period, the model predicts an increase of 2.1 percentage points in the capital owners' consumption share.

There is disagreement in the literature regarding the extent to which U.S. consumption inequality has increased. Studies by Kruger and Perri (2006) and Meyer and Sullivan (2013) find that consumption inequality has risen by much less than income inequality. Both studies

\footnotetext{
${ }^{24}$ The CES data and associated stata codes are the same as those used by Aguiar and Bils (2015) and are available from Mark Aguiar's website. The data excludes the top and bottom five percent of households sorted by pre-tax income. For comparion with the model, we treat households in the 80th through 95 th percentiles as the top quintile and households in the 5th through 80th percentiles as the remainder.
} 
measure consumption inequality using reported expenditures from the CES. However, Aguiar and Bils (2015) argue that the reported expenditure data for high-income households is subject to under-measurement error which has been growing over time. After designing a correction for the measurement error, they conclude that the rise in consumption inequality is close to the rise in income inequality.

\subsection{Model vs. Data: Real Equity Values}

A recent empirical study by Greenwald, Lettau, and Ludvigson (2014) finds that highly persistent "factor share shocks" which redistribute income between stockholders and nonstockholders are an important driver of U.S. stock prices over the period 1952 to 2012. Along these lines, Lansing (2015) develops a concentrated capital ownership model (similar to the one used here) in which persistent shocks to capital's share of income serve to substantially magnify the equity premium relative to a otherwise similar representative agent model.

While asset pricing is not our main focus here, it is interesting to examine the model's prediction for the path of real equity values over the period 1970 to 2013 . Recall from equation (6) that the market value of the capital owner's equity shares is given by $p_{t}=\left(1-\phi_{t} \tau_{t}\right) i_{t} / \lambda$. Figure 8 plots $p_{t}$ from the baseline simulation versus the real per capita market capitalization of the firms in S\&P 500 stock market index, where both series are indexed to 1 in $1970 .{ }^{25}$

The left panel of Figure 8 shows that the $\mathrm{S} \& \mathrm{P} 500$ market cap is far more volatile than $p_{t}$ in the model. Moreover, at the end of the data sample in 2013, the S\&P market cap is about $30 \%$ higher than the endpoint predicted by the model. These differences are perhaps not surprising given that our fully-rational model excludes the possibility of "bubbles" or "excess volatility," both which are the subject of a large literature. ${ }^{26}$

The right panel of Figure 8 plots changes in model equity values versus those in the data, where each series is scaled by its sample standard deviation. The correlation coefficient between the two series is 0.25 and statistically significant. These results lend support to the idea that there is link between shifting U.S. income shares and movements in equity values.

\subsection{Optimal and Pareto-improving Transfers}

Figure 9 plots the results of two normative experiments in which the time series of government transfers and income tax rates both depart from those in the baseline simulation. In the first experiment, we solve for the optimal time series of transfers $T_{t}^{*}$ that equates agents' marginal

\footnotetext{
${ }^{25}$ Data on the nominal S\&P 500 market capitalization in $\$$ billions are from Haver Analytics. We convert to real per capita values using the price index for personal consumption expenditures from NIPA Table 1.1.4 and the U.S. population data from NIPA Table 2.1 .

${ }^{26}$ Lansing and LeRoy (2014) provide a recent update on the excess volatility literature.
} 
utility of consumption each period such that $1 / c_{t}^{w}=1 / c_{t}^{c}$ for $t>t_{0} \cdot{ }^{27}$ In the second experiment, we solve for a Pareto-improving time series of transfers $T_{t}^{p}$ that achieves the less-ambitious condition $1 / c_{t}^{w}=1 /\left(\psi c_{t}^{c}\right)$ where $0<\psi<1$. We set $\psi=0.52875$ to achieve equal per-period welfare gains for capital owners and workers over a long simulation of the model. For each experiment, we compute the time series of income tax rates $\tau_{t}$ that are needed to satisfy the government budget constraint (14) each period, where other relevant variables take on the same values as those in the baseline simulation. Details of the computation procedure are contained in Appendix C.

The left panel of Figure 9 shows that $T_{t}^{*} / y_{t}$ jumps from $7.4 \%$ in 1970 (the starting value in the data) to $30 \%$ in 1971 . The ratio then trends upwards to $37 \%$ by the year 2013 , after which it remains constant because income inequality in the model stops rising by assumption. Interestingly, the correlation coefficient between the growth rate of $T_{t}^{*}$ and the growth rate of $y_{t}$ is -0.46 from 1970 to 2013. This is nearly identical to the observed correlation of -0.47 in the data, suggesting that U.S. government transfers exhibit the right amount of countercyclicality. ${ }^{28}$ In the right panel of Figure 9, we see that the corresponding income tax rate jumps from $39 \%$ in 1970 to $60 \%$ in 1971, and then trends upward to $64 \%$ by the year 2013. While fiscal policy shifts of this magnitude are obviously not realistic, they illustrate the severity of the actions that would have been needed to achieve consumption equality given the historical pattern of rising U.S. income inequality.

The second experiment shows that much milder policy actions would have sufficed to achieve welfare gains for everyone, according to the model. In this case, there is no need for an immediate jump in either transfers or tax rates. The ratio $T_{t}^{p} / y_{t}$ rises from $7.4 \%$ in 1970 to $18.2 \%$ in 2013 . The ending value is not much higher than the actual value of $14.6 \%$ observed in the data. In the data, the average compound growth rate of transfer payments is $3.42 \%$ per year. The Pareto-improving policy calls for $T_{t}^{p}$ to grow at an average compound growth rate of $3.96 \%$ per year. There is a jump in $T_{t}^{p} / y_{t}$ (and $T_{t}^{*} / y_{t}$ ) that occurs in the mid-1990s. This feature can be traced to the jump in the U.S. top quintile income share that occurred at the same time (Figure 1). The income tax rate that is needed to finance the Pareto-improving transfers goes from $39 \%$ in 1970 to $42 \%$ in 2013 . The ending value is well-within the range of average income tax rates observed in OECD countries. ${ }^{29}$

Figure 9 also plots the time series for $T_{t} / y_{t}$ and $\tau_{t}$ from the baseline simulation. The

\footnotetext{
${ }^{27}$ Equating agents' marginal utility of consumption would be the goal of a social planner who seeks to maximize the weighted-sum of agents' lifetime utilities, where weights correspond to the share of each agenttype in the population.

${ }^{28}$ Our exploration of the optimal redistributive transfer policy is necessarily brief here. For a more comprehensive treatment, see Piketty and Saez (2013b).

${ }^{29}$ According to Piketty and Saez (2013b), p. 141, the ratio of tax revenue to national income in OECD countries ranges from $35 \%$ to $50 \%$.
} 
baseline series for $T_{t} / y_{t}$ exactly replicates the U.S. data (Figure 2). The baseline series for $\tau_{t}$ ranges from a low of $36 \%$ to a high of $40 \%$. These values are realistic in comparison to tax rates that have been estimated directly for the U.S. economy. For the sample period 1970 to 2008, Gomme, Ravikumar and Rupert (2011) report labor income tax rates that range between $21 \%$ and $30 \%$ and capital income tax rates that range between $33 \%$ and $49 \%$.

\subsection{Welfare Analysis}

Table 2 summarizes the effects of rising income inequality for various model specifications. As detailed in Appendix D, welfare effects are calculated as the constant percentage amount by which each agent's consumption in the counterfactual scenario must be adjusted upward or downward each period to make lifetime utility equal to that in the baseline (or other) simulation. Table 2 also shows the long-run percentage shifts in the level of consumption for each type of agent, measured relative to the agent's consumption in the counterfactual scenario. The last column of Table 2 shows the long-run percentage output shift relative to the counterfactual scenario.

Table 2: Effects of Rising U.S. Income Inequality

\begin{tabular}{lccccc}
\hline \hline & \multicolumn{2}{c}{ Welfare Change } & \multicolumn{2}{c}{$\begin{array}{c}\text { Long-run } \\
\text { Consumption Shift }\end{array}$} \\
Model Specification & Capital Owners & Workers & Capital Owners & Workers & $\begin{array}{c}\text { Long-run } \\
\text { Output Shift }\end{array}$ \\
\hline Baseline simulation & 3.70 & -1.43 & 22.44 & 10.28 & 4.31 \\
Less patience, $\beta=0.958$ & 2.96 & -0.89 & 22.50 & 10.42 & 4.45 \\
Linear transition path for $\theta_{t}, \alpha_{t}$ & 4.80 & -0.35 & 22.44 & 10.28 & 4.31 \\
No business cycle shocks & 3.49 & -1.63 & 22.44 & 10.28 & 4.31 \\
Constant $\theta_{t}=\theta_{0}$ & -0.34 & 5.80 & -0.08 & 16.29 & -0.40 \\
Constant $T_{t} / y_{t}=T_{0} / y_{0}$ & 3.70 & -10.69 & 22.44 & -7.41 & 4.31 \\
Optimal $T_{t} / y_{t}$ & -36.84 & 17.05 & -29.97 & 32.48 & 2.21 \\
Pareto-improving $T_{t} / y_{t}$ & 0.28 & 0.28 & 13.99 & 14.02 & 4.10 \\
\hline
\end{tabular}

Notes: Welfare effects are measured by the percentage change in per-period consumption to make the agent indifferent between the transition simulation and the counterfactual scenario which holds income shares and the transfer-output ration constant at year 1970 values. The long-run consumption and output shifts are the percentage changes relative to the corresponding variables in the counterfactual scenario, as computed at the end of a 3000 period simulation.

For the baseline simulation, capital owners achieve a welfare gain of $3.7 \%$ of their per-period consumption while workers suffer a welfare loss of $1.4 \%$ of their per period consumption. The welfare effects are determined by changes in the time pattern of consumption for each type of agent in both the short-run and the long-run. These changes in the time patterns of consumption can be seen in the bottom two panels of Figure 4. Changes that take place in the short-run (i.e., closer to $t_{0}=1970$ ) have more influence on welfare due to discounting. 
For capital owners, welfare gains derive mainly from the post-2005 upward shift in their consumption path relative to the counterfactual. From Figure 1, we see that capital's share of income in the U.S. data experienced a sustained increase starting around the year 2005. The long-run upward consumption shift for capital owners is large - plateauing at $22.4 \%$ by the end of the simulation. The second row of Table 2 shows that capital owners' welfare gains shrink to $2.96 \%$ if agents are less patient such that $\beta=0.958$. The baseline simulation has $\beta=0.968$. A smaller value of $\beta$ reduces the lifetime utility benefit of the long-run consumption shift, thus shrinking the welfare gain for capital owners.

The time pattern of the worker's consumption is more complicated. From 1971 to 1985, the baseline path is above the counterfactual. This 15 -year period has a strong positive influence on the worker's welfare because of light discounting. During this time, the transfer-output ratio is rising faster than the top quintile income share, thus boosting the worker's consumption relative to the counterfactual. From 1985 to 2013, the rise in capital's share of income $\theta_{t}$ shrinks the worker's income share and the output contribution coming from labor-augmenting technological progress. This effect pushes down the worker's consumption relative to the counterfactual. Beyond 2013, the higher level of investment in the baseline economy (due to a higher $\theta_{t}$ ) contributes to more capital accumulation and more output, allowing the worker's consumption to eventually surpass the counterfactual, achieving a permanent upward level shift of $10.3 \%$. But these long-run consumption gains are heavily discounted. When agents are less patient with $\beta=0.958$, the 1970 to 1985 period takes on added-importance for the worker's welfare, generating a smaller loss of $0.89 \%$.

The above discussion highlights the importance of accurately modeling the historical paths of the U.S. income shares because these affect the time pattern of agents' consumption and hence welfare. To further illustrate this point, the third row of Table 2 shows the results of implementing a linear transition path for the income shares over the period 1970 to 2013 (while preserving the endpoints). This experiment improves the welfare outcomes for both types of agents. Relative to the baseline simulation, capital owners now achieve a larger gain $(4.8 \%$ versus $3.7 \%$ ) while workers suffer a smaller loss (0.35\% versus $1.4 \%)$. For capital owners, a linear transition causes $\theta_{t}$ to be higher during the early years of the simulation. For workers, a linear transition causes their income share $\left(1-\alpha_{t}\right)\left(1-\theta_{t}\right)$ to be higher from the mid-1990s onwards - a period when their baseline consumption path falls below the counterfactual.

The fourth row of Table 2 shows that shutting off the productivity shock innovations has only small effects on welfare relative to the baseline simulation. The model delivers the typical result that business cycles are not very important for welfare. Interestingly, the historical pattern of productivity shock innovations that we identify for the period 1971 to 2013 (Figure 5) serves to mildly improve the welfare outcomes for both types of agents relative to the 
no-shock simulation.

The fifth row of Table 2 holds the capital income share $\theta_{t}$ constant at the year 1970 value of $35 \%$. The time series for $\alpha_{t}, \tau_{t}, \phi_{t}, z_{t}$, and $T_{t} / y_{t}$ are identical to the baseline simulation while $g_{t}$ serves as the residual component of spending to absorb any differences in collected tax revenue. As expected, this experiment leads to much worse outcomes for capital owners and much better outcomes for the workers. Capital owners are now forced to help pay for the rising transfer-output ratio without the benefit of rapidly rising capital income stream.

The last three rows of Table 2 illustrate the sensitivity of the welfare results to assumptions about the path of redistributive transfers. When $T_{t} / y_{t}$ is held constant at its year 1970 value of $7.4 \%$, workers suffer a much larger welfare loss of $10.7 \%$ versus $1.4 \%$ in the baseline simulation. ${ }^{30}$ This result suggests that the historical pattern of U.S. transfer payments has been very effective in mitigating the negative impacts of rising income inequality on households who fall below the top quintile of the U.S. income distribution.

The optimal transfer policy that achieves consumption equality from 1971 onwards (Figure 9) produces a substantial welfare gain of $17 \%$ for workers. But for capital owners, the much higher income tax rate needed to finance the optimal transfers produces an enormous welfare loss of $36.8 \%$. Nevertheless, the economy with optimal transfers is still able to achieve a longrun upward shift in output of $2.2 \%$ relative to the counterfactual. The permanent upward shift is due to the permanent increase in $\theta_{t}$ which leads to more capital accumulation.

The Pareto-improving transfer policy achieves a small welfare gain of $0.28 \%$ for both capital owners and workers. Still, this outcome is a big improvement for workers relative to the $1.4 \%$ welfare loss suffered in the baseline simulation. Moreover, the economy continues to experience a substantial upward shift in output of $4.1 \%$ in the long-run. The Pareto-improving experiment suggests that realistic policy movements in the direction of more redistribution could be successful in combating the negative effects of rising income inequality without sacrificing long-run economic performance.

\section{Conclusion}

Over the past four decades, the U.S. economy experienced a profound upward shift in the share of income going to households who were already near the top of the income distribution. A key driver of this trend appears to be an increase in the rents paid to the narrow group of owners of financial and corporate wealth. The economic and political implications of increasinglyskewed income distributions in the U.S. and other countries have risen to the forefront of

\footnotetext{
${ }^{30}$ The welfare gain for capital owners is unaffected because the time series for $\tau_{t}, \phi_{t}$, and $z_{t}$ in this experiment are identical to those in the baseline simulation.
} 
current policy debates.

Our humble contribution is to try to assess the welfare consequences of rising U.S. income inequality using a standard growth model with two types of agents and concentrated-ownership of physical capital. The model is designed to exactly replicate the observed time paths of numerous U.S. macroeconomic variables over the period 1970 to 2013. The welfare consequences of rising income inequality depend crucially on changes in agents' consumption paths relative to a plausible counterfactual scenario. Our methodology ensures that agents' consumption paths are consistent with the evolution of U.S. macroeconomic variables over the same period. Our quantitative modeling approach has the additional advantage of providing us with full knowledge of the counterfactual scenario - something which is not possible using purely empirical methods.

According to our analysis, the increase in income inequality since 1970 has delivered large welfare gains to the top income quintile of U.S. households. For households outside this exclusive group, the welfare losses have been substantial, albeit mitigated by the doubling of the share of U.S. output devoted to redistributive transfers since 1970. Our analysis of the optimal transfer policy within the model suggests that historical U.S. transfer payments appear to exhibit the right amount of countercyclicality. In addition, we showed that a relatively modest increase in the historical growth rate of U.S. transfer payments (from $3.42 \%$ to $3.96 \%$ ) could have achieved small welfare gains for all households while continuing to deliver significant long-run output gains relative to the counterfactual scenario. Overall, our results suggest that there is room for policy actions to address the negative consequences of rising income inequality.

Two important caveats of our findings are in order. First, our framework does not allow us to say anything about changes in income inequality among agents in the lower four quintiles of the U.S. income distribution. A framework with more than two types of agents would be needed to study the consequences of any such changes. Second, we abstracted from endogenous human capital investment which, in the long-run, could help spread the benefits of biased technological change to agents who fall outside the top income group. 


\section{A Appendix: Capital Owner Decision Rules}

By combining equations (4), (11), and (12), the capital owner's equilibrium budget constraint can be written as

$$
c_{t}^{c}+\left(1-\phi_{t} \tau_{t}\right) i_{t}=\left(1-\tau_{t}\right)\left[\theta_{t}+\alpha_{t}\left(1-\theta_{t}\right)\right] y_{t} .
$$

Dividing both sides of the above expression by $c_{t}^{c}$ yields

$$
1+x_{t}=\left(1-\tau_{t}\right)\left[\theta_{t}+\alpha_{t}\left(1-\theta_{t}\right)\right] y_{t} / c_{t}^{c},
$$

where $x_{t} \equiv\left(1-\phi_{t} \tau_{t}\right) i_{t} / c_{t}^{c}$. Solving the above equation for $c_{t}^{c}$ yields equation (16) in the text. Equation (17) in the text follows directly from the definition of $x_{t}$.

The capital owner's first-order condition (6) can be re-written as follows

$$
\begin{aligned}
x_{t} & =E_{t} \beta\left[\frac{\lambda\left(1-\tau_{t+1}\right) \theta_{t+1} y_{t+1}}{c_{t+1}^{c}}+(1-\lambda) x_{t+1}\right], \\
& =E_{t} \beta\left[\frac{\lambda \theta_{t+1}}{\theta_{t+1}+\alpha_{t+1}\left(1-\theta_{t+1}\right)}\left(1+x_{t+1}\right)+(1-\lambda) x_{t+1}\right], \\
& =E_{t} \beta\left[\lambda s_{t+1}\left(1+x_{t+1}\right)+(1-\lambda) x_{t+1}\right]
\end{aligned}
$$

where the second version of the expression is obtained by using equation (A.2) evaluated at time $t+1$. The third version of the expression employs the definition of $s_{t+1}$ which evolves according to the stationary law of motion (10). Notice that the rational expectation solution for $x_{t}$ will depend on the state variable $s_{t}$ but not on the tax wedges $\tau_{t}$ or $\phi_{t}$. The tax wedges are subsumed within the definition of $x_{t}$.

To solve for the approximate decision rule $x_{t}=x\left(s_{t}\right)$, we first log linearize the right-side of equation (A.3) to obtain

$$
x_{t}=E_{t} \mathrm{a}_{0}\left[\frac{x_{t+1}}{\widetilde{x}}\right]^{\mathrm{a}_{1}}\left[\frac{s_{t+1}}{\widetilde{s}}\right]^{\mathrm{a}_{2}},
$$

where $\mathrm{a}_{0}, \mathrm{a}_{1}$, and $\mathrm{a}_{2}$ are Taylor-series coefficients. The expressions for the Taylor-series coefficients are

$$
\begin{aligned}
\mathrm{a}_{0} & =\beta[\lambda \widetilde{s}(1+\widetilde{x})+(1-\lambda) \widetilde{x}] \\
\mathrm{a}_{1} & =\frac{[\lambda \widetilde{s}+(1-\lambda)] \widetilde{x}}{\lambda \widetilde{s}(1+\widetilde{x})+(1-\lambda) \widetilde{x}}, \\
\mathrm{a}_{2}= & \frac{\lambda \widetilde{s}(1+\widetilde{x})}{\lambda \widetilde{s}(1+\widetilde{x})+(1-\lambda) \widetilde{x}},
\end{aligned}
$$

where the approximation is taken around the ergodic mean such that $\widetilde{x} \equiv \exp \left\{E\left[\log \left(x_{t}\right)\right]\right\}$ and $\widetilde{s} \equiv \exp \left\{E\left[\log \left(s_{t}\right)\right]\right\}$.

We conjecture that the decision rule for $x_{t}$ takes the form

$$
x_{t}=\widetilde{x}\left[\frac{s_{t}}{\widetilde{s}}\right]^{\gamma} \text {. }
$$


The conjectured form of the solution (A.8) is iterated ahead one period and then substituted into the right-side of equation (A.4) together with the law of motion for $s_{t+1}$ from equation (10). After evaluating the conditional expectation and then collecting terms, we have

$$
x_{t}=\underbrace{\mathrm{a}_{0} \exp \left[\frac{1}{2}\left(\mathrm{a}_{2}+\gamma \mathrm{a}_{1}\right)^{2} \sigma_{u}^{2}\right]}_{=\widetilde{x}} \times[\frac{s_{t}}{\widetilde{s}} \underbrace{\rho\left(\mathrm{a}_{2}+\gamma \mathrm{a}_{1}\right)}_{=\gamma}
$$

which yields two equations in the two unknown solution coefficients $\widetilde{x}$ and $\gamma$.

From equations (A.5) through (A.7) and (A.9), we see that the value of $\lambda$ will influence the value of $\widetilde{x}$. To calibrate the value of $\lambda$, we first use the investment decision rule (17) to eliminate the investment wedge $\phi_{t}$ from the government budget constraint (14). Solving the resulting expression for $1-\tau_{t}$ yields

$$
1-\tau_{t}=\frac{1-\left(g_{t} / y_{t}+T_{t} / y_{t}+i_{t} / y_{t}\right)}{1-q_{t}}
$$

where $q_{t} \equiv x\left(s_{t}\right)\left[\theta_{t}+\alpha_{t}\left(1-\theta_{t}\right)\right] /\left[1+x\left(s_{t}\right)\right]$. Equation (A.10) then implies

$$
1-\phi_{t} \tau_{t}=\frac{1-q_{t}\left(1-\phi_{t}\right)-\phi_{t}\left(g_{t} / y_{t}+T_{t} / y_{t}+i_{t} / y_{t}\right)}{1-q_{t}}
$$

Substituting equations (A.10) and (A.11) into the investment decision rule (17) and then solving for $q_{t}$ yields

$$
q_{t}=\frac{i_{t} / y_{t}\left[1-\phi_{t}\left(g_{t} / y_{t}+T_{t} / y_{t}+i_{t} / y_{t}\right)\right]}{1-g_{t} / y_{t}-T_{t} / y_{t}-\phi_{t}\left(i_{t} / y_{t}\right)}
$$

Next, we choose a target value for the average investment expensing fraction $\phi_{t}$ that is based a standard depreciation allowance with a depreciation rate of $\delta=0.06$ and an investment-capital ratio of $i_{t} / k_{t}=0.08$. Specifically, we choose $\phi_{t} i_{t}=\delta k_{t}$ such that $\phi_{t}=\delta\left(k_{t} / i_{t}\right)=0.06 /(0.08)=$ 0.748. Given this value for $\phi_{t}$ and the 1970 to 2013 average values for the U.S. macroeconomic ratios $g_{t} / y_{t}, T_{t} / y_{t}$, and $i_{t} / y_{t}$, we solve equation (A.12) for the target value of $q_{t}$. The target value of $q_{t}$ implies the following target value for $x_{t}=q_{t} /\left[\theta_{t}+\alpha_{t}\left(1-\theta_{t}\right)-q_{t}\right]=0.3350$, where we have employed the 1970 to 2013 average value of 0.4727 for the top quintile income share given by $\theta_{t}+\alpha_{t}\left(1-\theta_{t}\right)$. Using equation (A.9), we solve for the value of $\lambda=0.0151$ to achieve the target value $\widetilde{x}=0.3350$. Also using equation (A.9), we obtain $\gamma=0.2331$ for the baseline calibration.

From equation (A.8) and the definition of $s_{t}$ from equation (9), we have

$$
\frac{\partial x_{t}}{\partial \theta_{t}}=\frac{\partial x_{t}}{\partial s_{t}} \frac{\partial s_{t}}{\partial \theta_{t}}=\frac{\gamma x_{t}}{\theta_{t}+\alpha_{t}\left(1-\theta_{t}\right)}>0,
$$

which shows that an increase in $\theta_{t}$ causes the capital owner to devote more resources to investment instead of consumption. 


\section{B Appendix: Numerical Simulation Procedure}

This appendix describes our procedure for the baseline simulation. Given the agents' decision rules (15), (16), and (17), together with the government budget constraint (14), we solve for the time series of tax wedges $\tau_{t}$ and $\phi_{t}$ so that the model exactly replicates the observed time paths of the four U.S. macroeconomic ratios plotted in Figure 2. Simultaneously, we solve for a time series of productivity shocks $z_{t}$ that cause the model to exactly replicate the denominator of the U.S. macroeconomic ratios, i.e., real per capita output over the period 1970 to 2013.

From equation (A.10) we have

$$
\tau_{t}=\frac{g_{t} / y_{t}+T_{t} / y_{t}+i_{t} / y_{t}-q_{t}}{1-q_{t}}
$$

Given the observed U.S. time series for $s_{t}$ from Figure 3, we use the decision rule (A.8) to compute $x_{t}=x\left(s_{t}\right)$ from 1970 to 2013 . The corresponding time series for $\theta_{t}+\alpha_{t}\left(1-\theta_{t}\right)$ is given by the U.S. top quintile share, as plotted in the top right panel of Figure 1. These two series are combined to form the time series for $q_{t} \equiv x\left(s_{t}\right)\left[\theta_{t}+\alpha_{t}\left(1-\theta_{t}\right)\right] /\left[1+x\left(s_{t}\right)\right]$. The computed time series for $q_{t}$ is then substituted into equation (B.1) together with the observed U.S. time series for $g_{t} / y_{t}, T_{t} / y_{t}$, and $i_{t} / y_{t}$, as plotted in Figure 2. This procedure yields a time series for the unobserved income tax wedge $\tau_{t}$.

Next, given the time series for $\tau_{t}$, we use the investment decision rule (17) to recover the time series for the unobserved investment tax wedge $\phi_{t}$ as follows

$$
\phi_{t}=\frac{i_{t} / y_{t}-q_{t}\left(1-\tau_{t}\right)}{\left(i_{t} / y_{t}\right) \tau_{t}}
$$

where $q_{t}$ and $i_{t} / y_{t}$ are the same time series used in the computation of $\tau_{t}$.

The aggregate resource constraint for the model economy implies

$$
c_{t} / y_{t}=1-g_{t} / y_{t}-i_{t} / y_{t}
$$

We take the time series for $g_{t} / y_{t}$ directly from U.S. data, as plotted in the bottom left panel of Figure 2. The computed time series for $\tau_{t}$ and $\phi_{t}$ ensure that we exactly replicate the observed U.S. time series for $i_{t} / y_{t}$. Since we define $y_{t}$ in the data as $c_{t}+i_{t}+g_{t}$ (footnote 9 ), our procedure ensures that we also replicate the observed U.S. time series for $c_{t} / y_{t}$, as plotted in the top left panel of Figure 2.

The final step is to compute a time series of productivity shocks $z_{t}$ that cause the model to exactly replicate the path of U.S. real per capita output from 1970 to 2013. The level of real output in the data is normalized to 1.0 in the year 1970. We calibrate the value of $A$ in the production function ( 7$)$ to yield $y_{t}=1$ at $t_{0}=1970$. The calibration assumes $k_{t} / y_{t}=0.93$ in 1970 which is obtained by combining the observed U.S. value of $i_{t} / y_{t}=0.075$ in 1970 with the calibration target of $i_{t} / k_{t}=0.08$. Given the computed time series for $\tau_{t}$ and $\phi_{t}$ described above, we conjecture a time series for $z_{t}$ from 1970 to 2013 with $z_{0}=0$. Using the agents' decision rules, we then simulate the model. After each simulation, we compute a new time 
series for $z_{t}$ as follows

$$
z_{t}=\frac{\log \left(y_{t}\right)-\log \left\{A k_{t}^{\theta_{t}}\left[\left(\ell^{c}\right)^{\alpha_{t}}\left(n \ell^{w}\right)^{1-\alpha_{t}}\right]^{1-\theta_{t}}\right\}}{1-\theta_{t}},
$$

where $y_{t}$ is given by the normalized real output series from the U.S. data, $\theta_{t}$ and $\alpha_{t}$ are pinned down by the income share data, and $k_{t}$ is the model capital stock series implied by the law of motion (5) with $i_{t}$ determined by the capital owner's decision rule (17). We repeat this procedure until the computed time series for $z_{t}$ does not change from one simulation to the next. In practice, convergence is achieved after about 8 simulations. For $t>2013$, we assume that the shock innovations $\varepsilon_{t}$ and $u_{t}$ are zero each period while $\theta_{t}, \alpha_{t}, \tau_{t}$, and $\phi_{t}$ are held constant at year 2013 values. As a result, the macroeconomic ratios $c_{t}^{c} / y_{t}, c_{t}^{w} / y_{t}, i_{t} / y_{t}, g_{t} / y_{t}$, and $T_{t} / y_{t}$ also remain constant at year 2013 values.

\section{Appendix: Optimal and Pareto-improving Transfers}

This appendix outlines our procedure for computing the optimal and Pareto-improving time series of redistributive transfers plotted in Figure 9. The optimal level of transfers achieves the condition $1 / c_{t}^{w}=1 / c_{t}^{c}$, or equivalently, $c_{t}^{w}=c_{t}^{c}$, for each $t>t_{0}$. Equating the two consumption decision rules (15) and (16) and then solving for the required transfer-output ratio yields

$$
T_{t}^{*} / y_{t}=\left(1-\tau_{t}\right)\left\{\frac{n}{1+x\left(s_{t}\right)}\left[\theta_{t}+\alpha_{t}\left(1-\theta_{t}\right)\right]-\left(1-\alpha_{t}\right)\left(1-\theta_{t}\right)\right\},
$$

where $T_{t}^{*}$ denotes the optimal level of transfers.

Starting from equation (14), the equilibrium version of the government budget constraint can be written as

$$
\begin{aligned}
g_{t} / y_{t}+T_{t}^{*} / y_{t} & =\tau_{t}\left(1-\phi_{t} i_{t} / y_{t}\right) \\
& =\tau_{t}\left\{1-\phi_{t} \frac{x\left(s_{t}\right)}{1+x\left(s_{t}\right)}\left(\frac{1-\tau_{t}}{1-\phi_{t} \tau}\right)\left[\theta_{t}+\alpha_{t}\left(1-\theta_{t}\right)\right]\right\},
\end{aligned}
$$

where the second version of the expression is obtained by substituting in the capital owner's investment decision rule (17). Substituting $T_{t}^{*} / y$ from equation (C.1) into equation (C.2) yields a quadratic equation in $\tau_{t}$ that is solved each period for $t>t_{0} \cdot{ }^{31}$ The other variables in the quadratic equation are $\theta_{t}, \alpha_{t}, x\left(s_{t}\right), g_{t} / y_{t}$, and $\phi_{t}$ which take on the same values as those in the baseline simulation.

To compute the Pareto-improving level of transfers, we solve for the required transferoutput ratio to achieve the condition $1 / c_{t}^{w}=1 /\left(\psi c_{t}^{c}\right)$, or equivalently $c_{t}^{w}=\psi c_{t}^{c}$, where $0<$ $\psi<1$. The computation is similar to that for optimal transfers, except that the quadratic equation that is solved each period for $\tau_{t}$ now includes the constant $\psi$. When $\psi=1$, we recover

\footnotetext{
${ }^{31}$ The quadratic equation has two solutions. We choose the solution that lies on the upward-sloping portion of the Laffer curve.
} 
the optimal level of transfers. Through repeated simulations of the model, we guess and verify that the value $\psi=0.528750$ achieves the result $\Delta^{w}=\Delta^{c}=0.00277708$, where $\Delta^{w}$ and $\Delta^{c}$ are the per-period welfare effects described in Appendix D.

\section{Appendix: Welfare Calculation}

Welfare effects are calculated as the constant percentage amount by which each agent's consumption in the counterfactual scenario (which holds $\theta_{t}, \alpha_{t}$, and $T_{t} / y_{t}$ constant at year 1970 values) must be adjusted upward or downward each period to make lifetime utility equal to that in the transition simulation. Specifically, we find $\Delta^{w}$ and $\Delta^{c}$ that solve the following two equations

$$
\begin{aligned}
\sum_{t=t_{0}}^{\infty} \beta^{t} \log \left(c_{t}^{w}\right) & =\sum_{t=t_{0}}^{\infty} \beta^{t} \log \left[\bar{c}_{t}^{w}\left(1+\Delta^{w}\right)\right], \\
\sum_{t=t_{0}}^{\infty} \beta^{t} \log \left(c_{t}^{c}\right) & =\sum_{t=t_{0}}^{\infty} \beta^{t} \log \left[\bar{c}_{t}^{c}\left(1+\Delta^{c}\right)\right],
\end{aligned}
$$

where $c_{t}^{w}$ and $c_{t}^{c}$ for $t=0 \rightarrow \infty$ are the consumption paths in the transition simulation and $\bar{c}_{t}^{w}$ and $\bar{c}_{t}^{c}$ for $t=0 \rightarrow \infty$ are the consumption paths in the counterfactual scenario. The infinite sums in (D.1) and (D.2) are approximated by sums over a 3000 period simulation, after which the results are not changed. The initial conditions correspond to year $t_{0}=1970$ values for all variables. 


\section{References.}

Aguiar, M., and M. Bils 2011 Has Consumption Inequality Mirrored Income Inequality? NBER Working Paper 16807.

Aguiar, M., and M. Bils 2015 Has Consumption Inequality Mirrored Income Inequality? American Economic Review, forthcoming.

Alvaredo, F., A.B. Atkinson, T. Piketty, and E. Saez 2013 The Top 1 Percent in International and Historical Perspective, Journal of Economic Perspectives 27(3), 2-20.

Attanasio, O., and S. Davis 1996 Relative Wage Movements and the Distribution of Consumption, Journal of Political Economy 104, 1227-1262.

Attanasio, O., E. Hurst, and L. Pistaferri 2012 The Evolution of Income, Consumption, and Leisure Inequality in the U.S., 1980-2010, NBER Working Paper 17982.

Cassou, S.P. and K.J. Lansing 2006 Tax Reform with Useful Public Expenditures, Journal of Public Economic Theory 8, 631-676.

Chari, V.V., P.J. Kehoe, and E.R. McGrattan 2007 Business Cycle Accounting, Econometrica $75,781-836$.

Danthine, J.-P., J.B. Donaldson, and P. Siconolfi 2008 Distribution Risk and Equity Returns, in R. Mehra (ed.), Handbook of the Equity Risk Premium. Amsterdam: North-Holland, pp. 415-462.

Goldin, C. and L.F. Katz 2007 The Race between Education and Technology: The Evolution of U.S. Educational Wage Differentials, 1890 to 2005, NBER Working Paper 12984.

Goldin, C. and L.F. Katz 2008 The Race between Education and Technology. Cambridge MA: Harvard University Press.

Gomme, P., B. Ravikumar, and P. Rupert 2011 The Return to Capital and the Business Cycle, Review of Economic Dynamics 14, 262-278.

Gottschalk, P., and S. Danziger 2005 Inequality of Wage Rates, Earnings and Family Income in the United States, 1975-2002, Review of Income and Wealth 51, 231-254.

Greenwald, D.L., M. Lettau, and S.C. Ludvigson 2014 The Origins of Stock Market Fluctuations, National Bureau of Economic Research, Working Paper 19818.

Greenwood J. and M. Yörükoğlu 19971974 Carnegie-Rochester Conference Series on Public Policy 46, 49-96.

Guvenen, F. 2009 A Parsimonious Macroeconomic Model for Asset Pricing, Econometrica 77, 1711-1750.

Heathcote, J., K. Storesletten, and G.L. Violante 2010 The Macroeconomic Implications of Rising Wage Inequality in the United States, Journal of Political Economy 118, 681-722.

Heathcote, J., K. Storesletten, and G.L. Violante 2011 From Wages to Welfare: Decomposing Gains and Losses from Rising Inequality, Working Paper.

Heaton, J. and D. Lucas 2000 Stock Prices and Fundamentals, in B.S. Bernanke and J.J. Rotemberg (eds.), NBER Macroeconomics Annual 1999. Cambridge MA: MIT Press, pp. 213-264.

Hornstein, A. and P. Krusell 1996 Can Technology Improvements Cause Productivity Slowdowns? NBER Macroeconomics Annual 11. Cambridge MA: MIT Press, pp. 209-259.

Jermann, U.J. 1998 Asset Pricing in Production Economies Journal of Monetary Economics $41,257-275$.

Karabarbounis, L. and B. Neiman 2014 The Global Decline of the Labor Share, Quarterly Journal of Economics 129, 61-103. 
Krueger, D. and F. Perri 2006 Does Income Inequality Lead to Consumption Inequality? Evidence and Theory, Review of Economic Studies 73, 163-193.

Krusell, P., L. Ohanian, J.V. Ríos-Rull, and G.L. Violante 2000 Capital-Skill Complementarity and Inequality: A Macroeconomic Analysis, Econometrica 68, 1029-1054.

Krusell, P. 2002 Time-Consistent Redistribution, European Economic Review 46, 755-769.

Kumhof, M., R. Rancière, and P. Winant 2015 Inequality, Leverage and Crises: The Case of Endogenous Default, American Economic Review 105, 1217-1245.

Judd, K.L. 1985 Redistributive Taxation in a Simple Perfect Foresight Model, Journal of Public Economics 28, 59-83.

Lansing, K.J. 1999 Optimal Redistributive Capital Taxation in a Neoclassical Growth Model, Journal of Public Economics 73, 423-453.

Lansing, K.J. 2012 Speculative Growth, Overreaction, and the Welfare Cost of Technologydriven Bubbles, Journal of Economic Behavior and Organization 83, 461-483.

Lansing, K.J. 2015 Asset Pricing with Concentrated Ownership of Capital and Distribution Shocks, Amercan Economic Journal-Macroeconomics, forthcoming.

Lansing, K.J. and S.F. LeRoy 2014 Risk Aversion, Investor Information, and Stock Market Volatility, European Economic Review 70, 88-107.

Meyer, B.D. and J.X. Sullivan 2013 Consumption and income inequality in the U.S. since the 1960s, Working paper, http://www3.nd.edu/ jsulliv4/Inequality3.6.pdf.

Piketty, T. 2014 Capital in the Twenty-First Century. Cambridge, MA: Harvard University Press.

Piketty, T., and E. Saez 2003 Income Inequality in the United States, 1913-1998, Quarterly Journal of Economics 118, 1-39.

Piketty, T., and E. Saez 2013a Top Incomes and the Great Recession: Recent Evolutions and Policy Implications, IMF Economic Review 61, 456-478.

Piketty, T., and E. Saez 2013b Optimal Labor Income Taxation, in A.J. Auerbach, R. Chetty, M. Feldstein, and E. Saez (eds.), Handbook of Public Economics Vol. 5. Amsterdam: Elsevier, pp. 391-474.

Piketty, T., E. Saez, and S. Stantcheva 2014 Optimal Taxation of Top Labor Incomes: A Tale of Three Elasticities, American Economic Journal: Economic Policy 6, 230-271.

Ríos-Rull, J.V. and R. Santaeulàlia-Llopis 2010 Redistribution Shocks and Productivity Shocks, Journal of Monetary Economics 57, 931-948.

Wolff, E.N. 2010 Recent Trends in Household Wealth in the United States: Rising Debt and the Middle-Class Squeeze - an Update to 2007, Levy Economics Institute, Working Paper 589.

Young, A.T., 2004. Labor's share fluctuations, biased technical change, and the business cycle, Review of Economic Dynamics 7, 916-931 
U.S. Top Decile Income Share

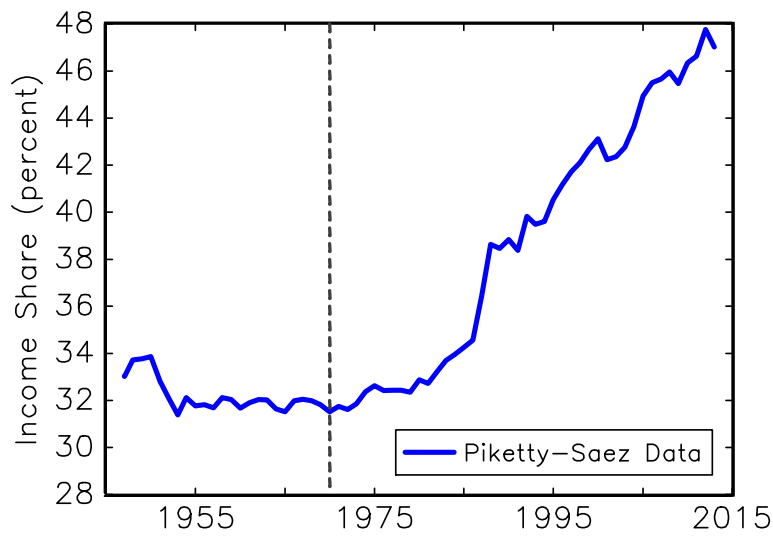

U.S. Household Real Income

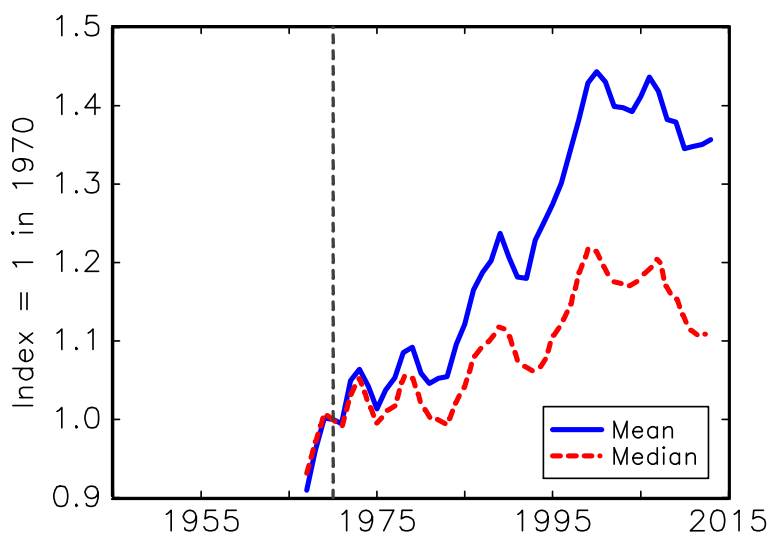

U.S. Top Quintile Income Share

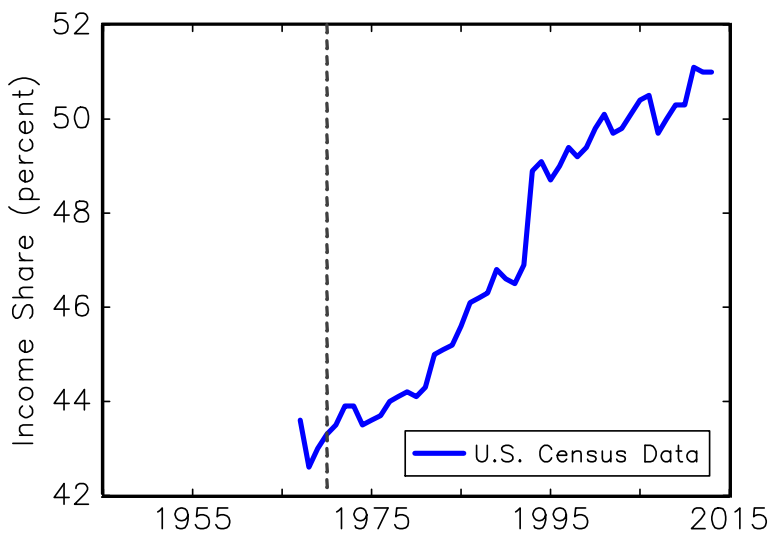

U.S. Capital Share of Total Income

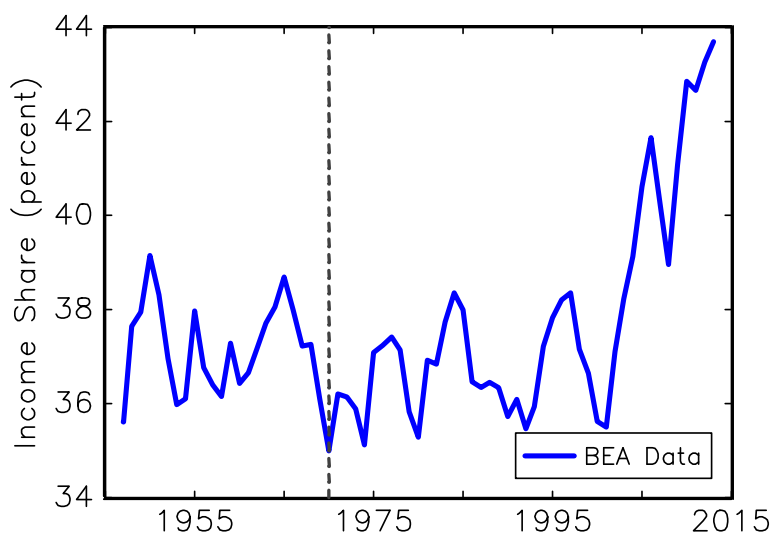

Figure 1: The increase in U.S. income inequality over the past four decades can be traced to gains made by those near the top of the income distribution where financial wealth and corporate stock ownership is highly concentrated. 
U.S. Personal Consumption Expenditures

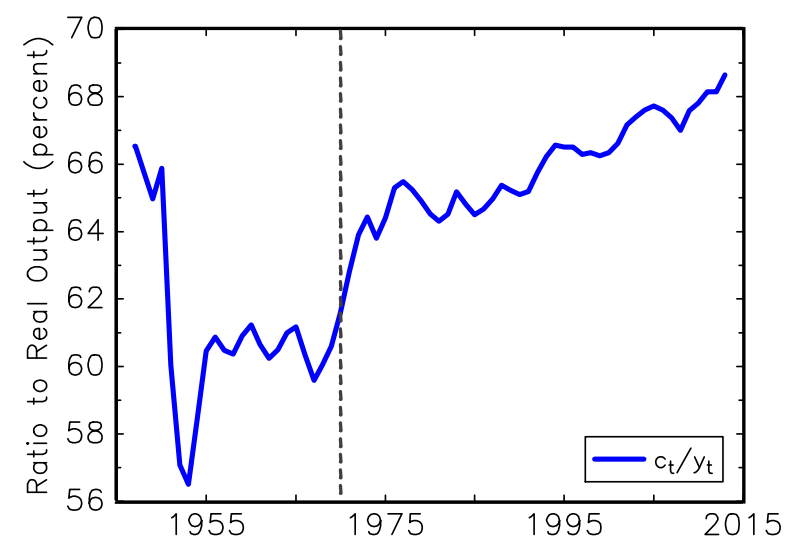

U.S. Govt. Consumption and Investment

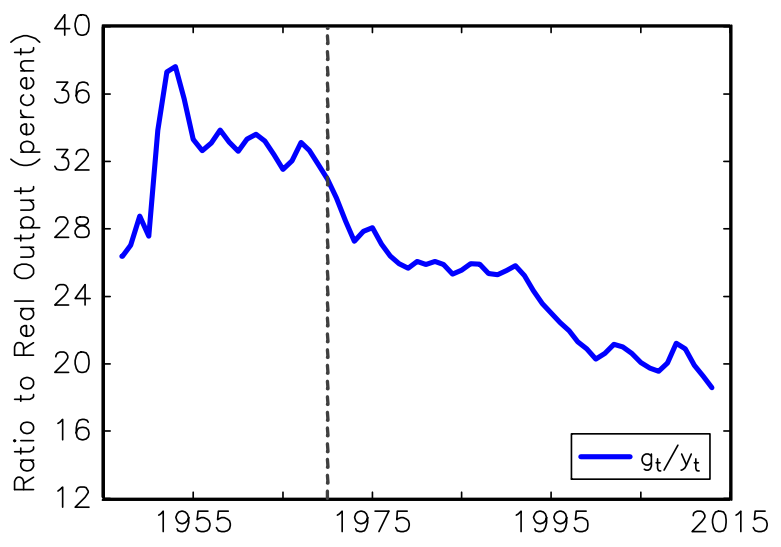

U.S. Nonresidential Private Investment

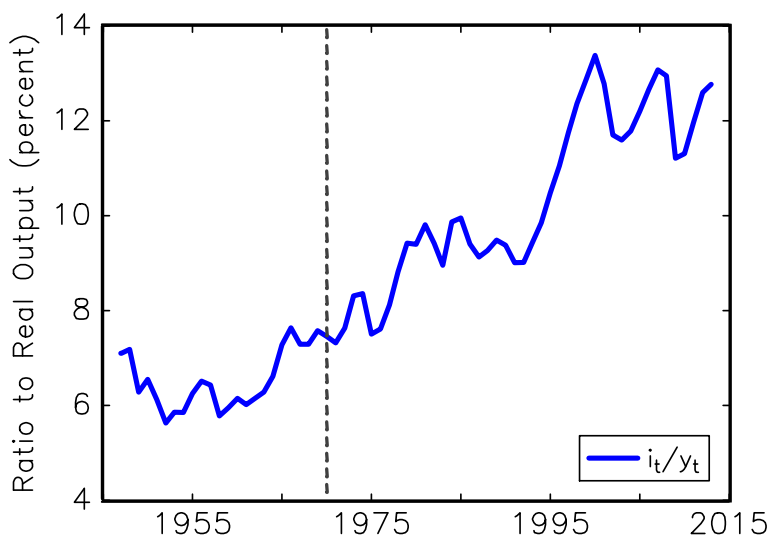

U.S. Govt. Transfer Payments to Individuals

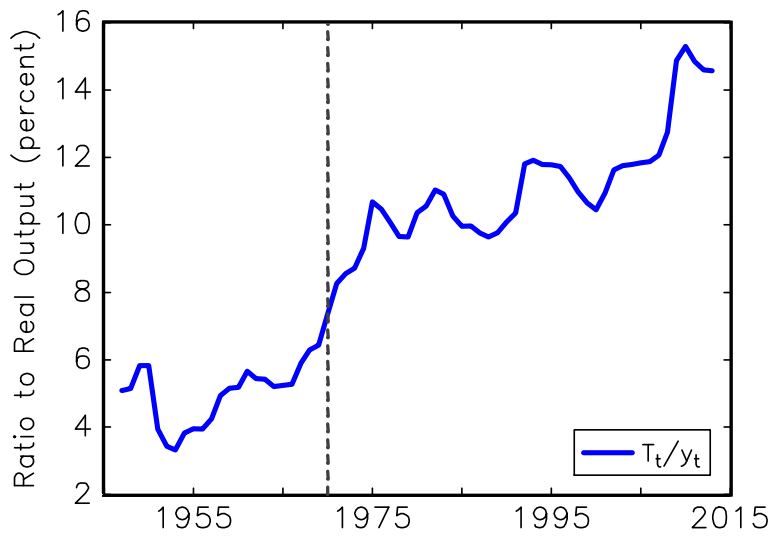

Figure 2: The baseline simulation exactly replicates the observed U.S. time paths for the ratios $c_{t} / y_{t}, i_{t} / y_{t}, g_{t} / y_{t}$, and $T_{t} / y_{t}$ over the period 1970 to 2013 . The vertical dashed line marks $t_{0}=1970$. 


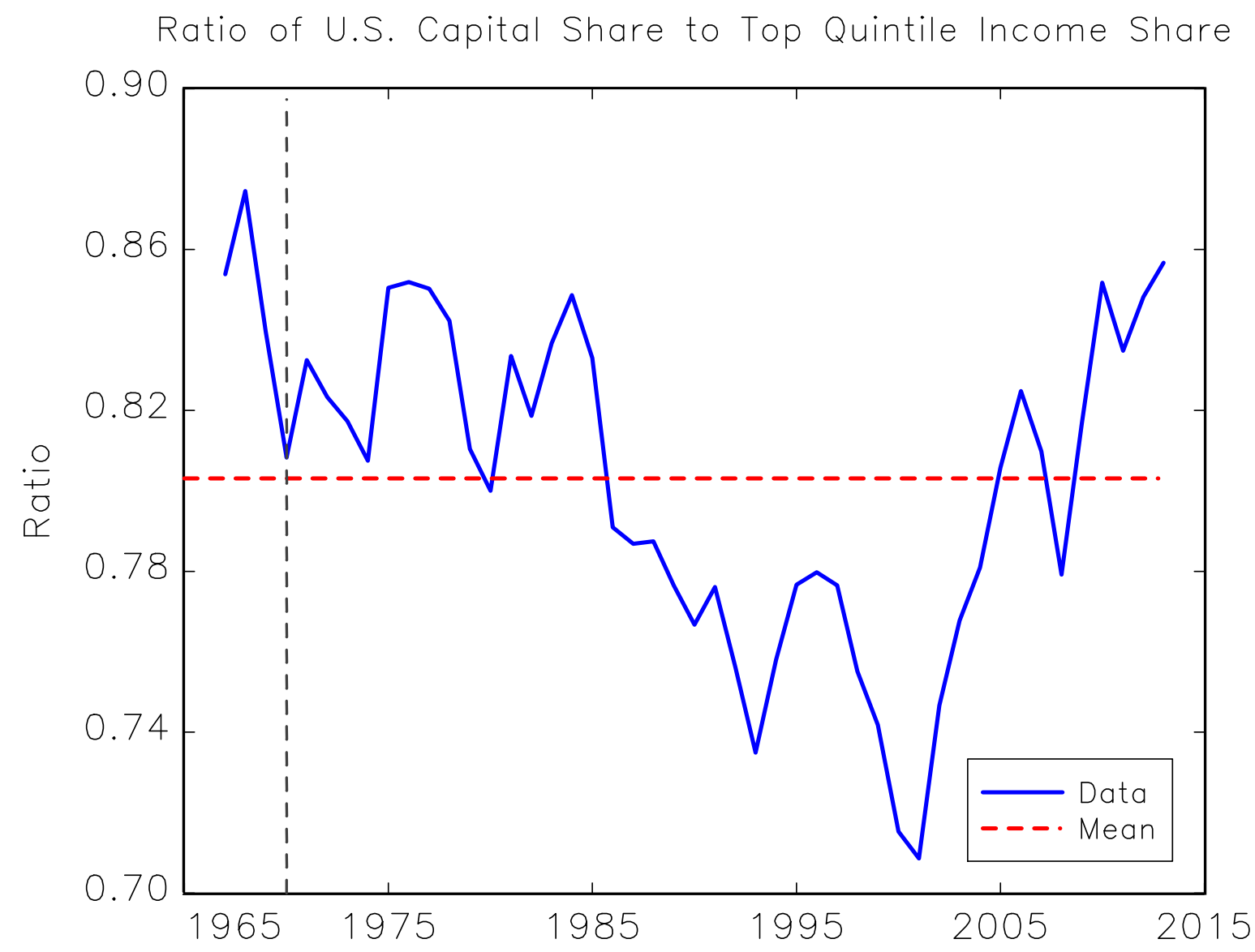

Figure 3: The ratio of capital's share of income to the top quintile income share in U.S. data appears stationary but persistent. In the model, this ratio is a state variable that pins down the capital owner's tax-adjusted income-consumption ratio. 

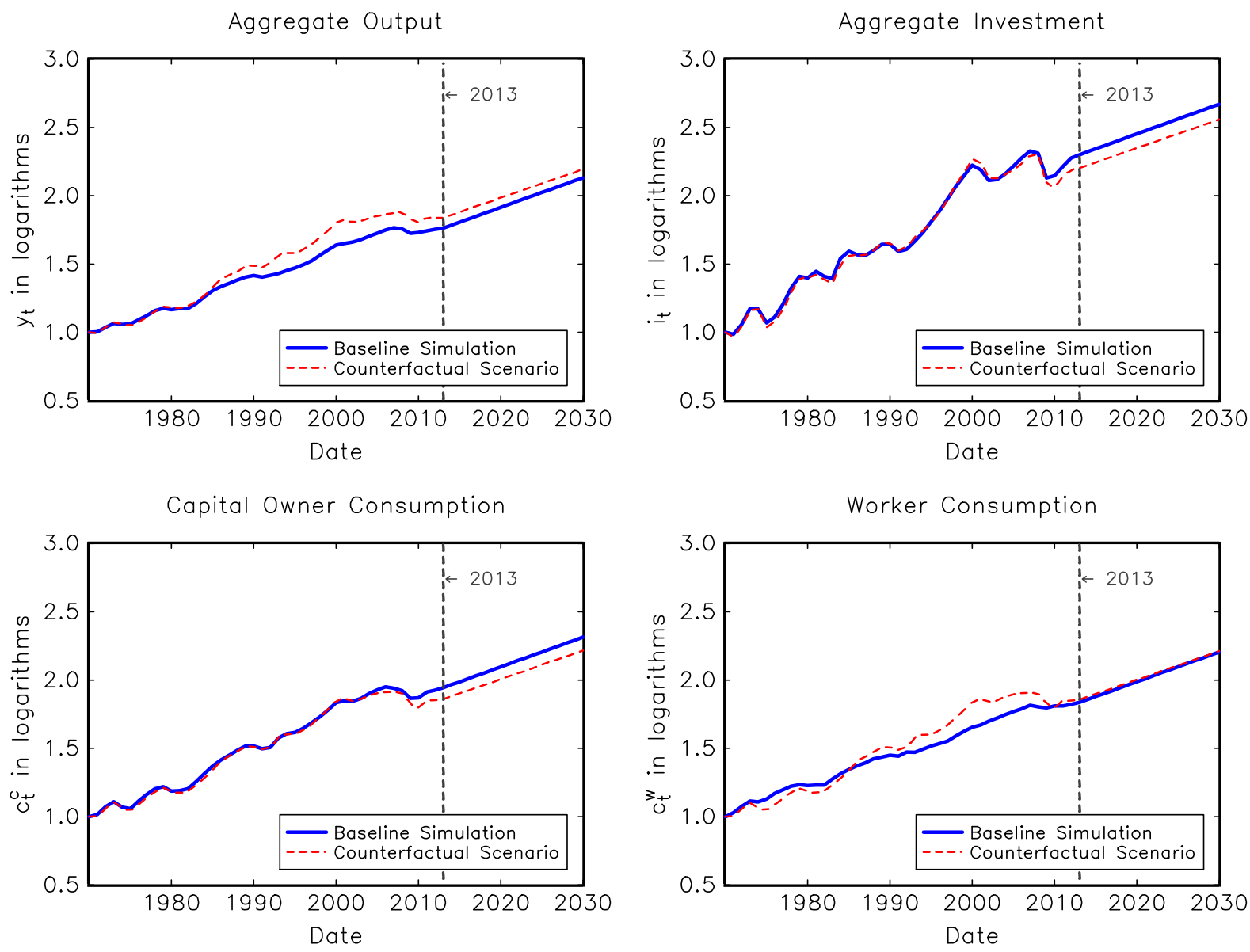

Figure 4: The figure plots the paths of model variables in the baseline simulation versus a counterfactual scenario in which the income shares and the transfer-output ratio are held constant at year 1970 values. It takes a long time for the model transition dynamics to play out. All four variables in baseline simulation eventually surpass the corresponding levels in the counterfactual scenario. This gives rise to long-run upward level shifts in consumption for both capital owners and workers relative to the counterfactual scenario. But the short-run consumption paths are much more important for welfare. 

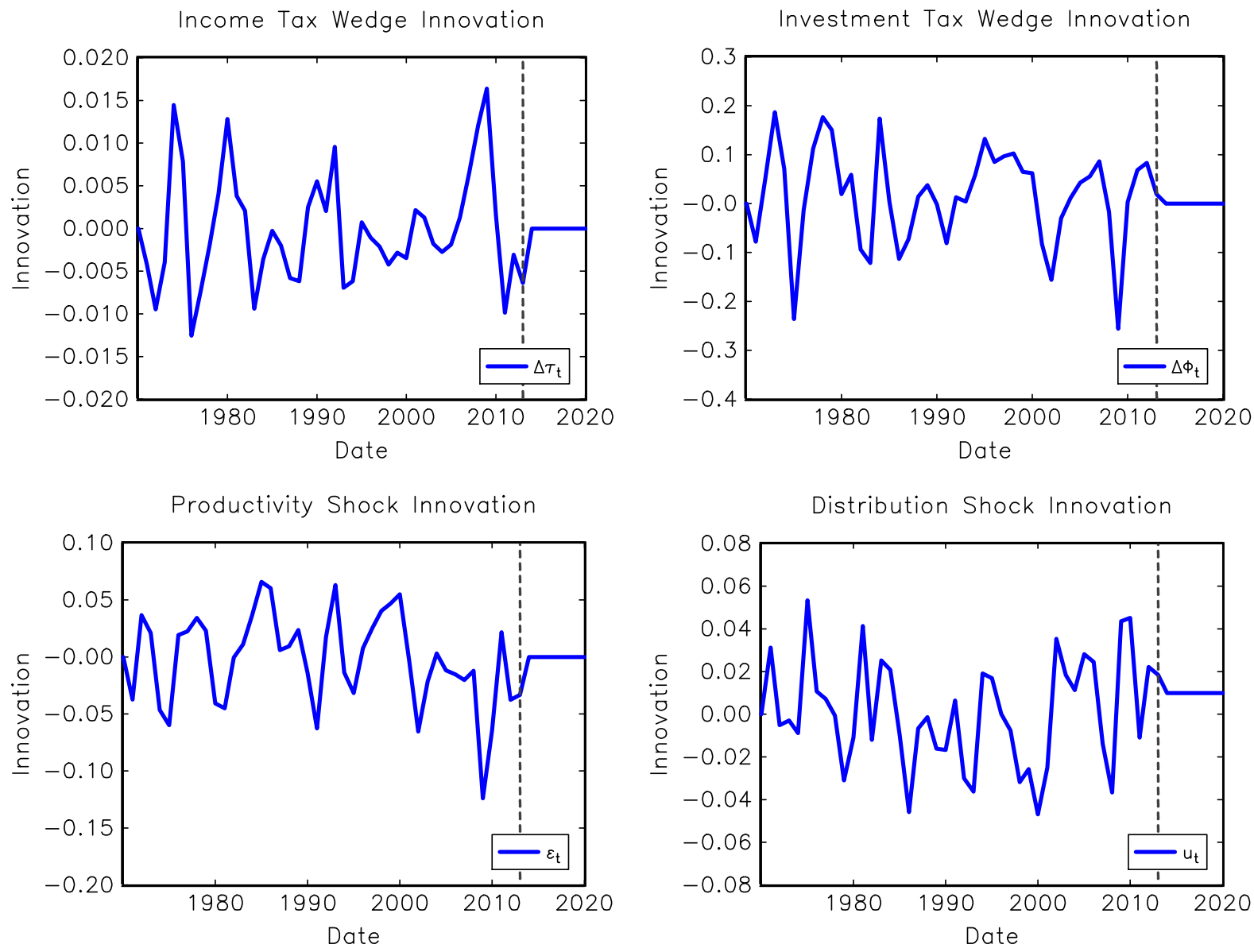

Figure 5: The figure plots the time series of tax wedge innovations and stochastic shock innovations that are needed to make the baseline simuation exactly replicate the paths of U.S. macroeconomic variables over the period 1970 to 2013. By construction, the innovations are zero at $t_{0}=1970$ and for $t>2013$. The vertical dashed line marks $t=2013$. 

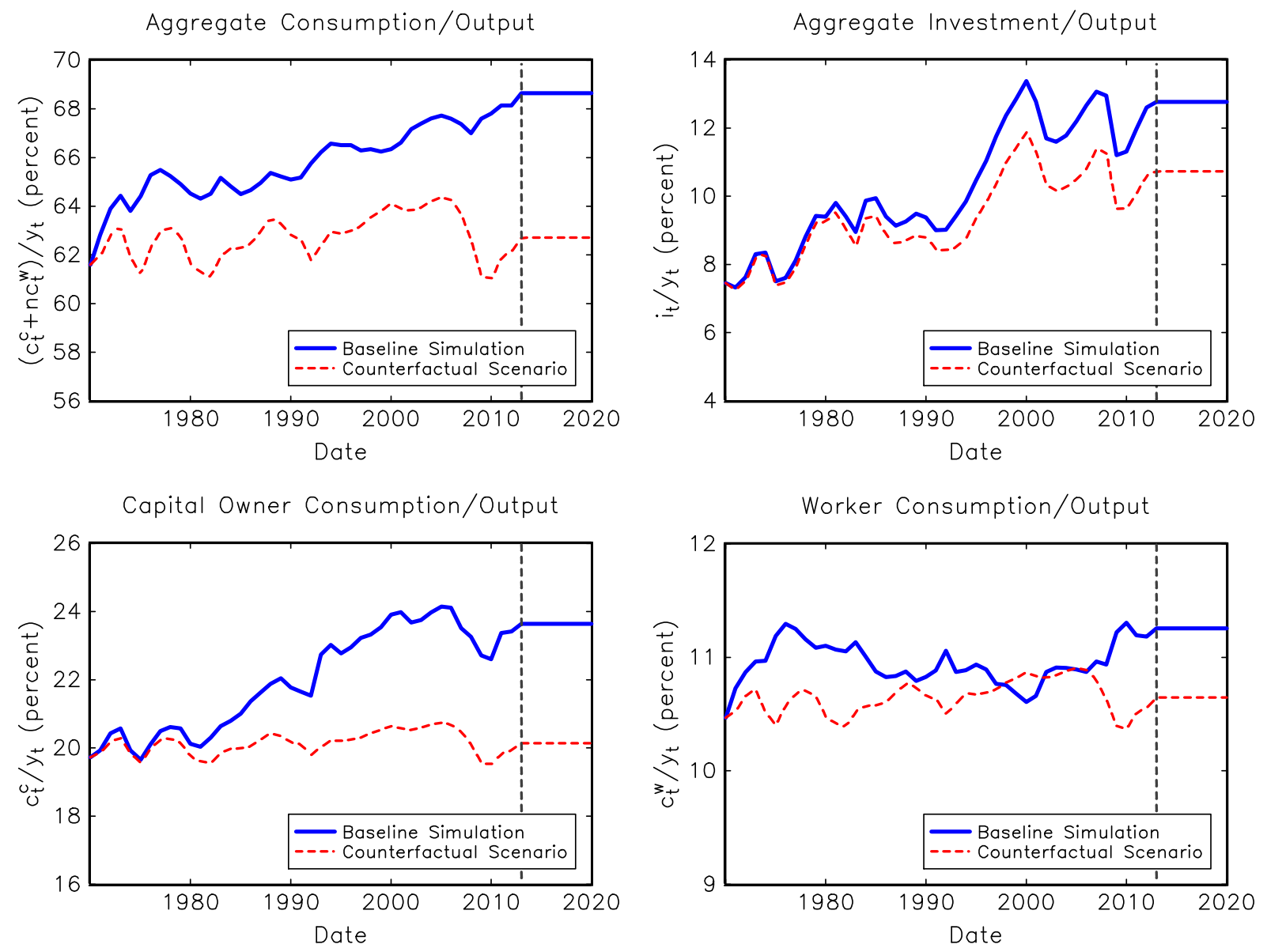

Figure 6: The baseline simulation exactly replicates the observed paths of aggregate $c_{t} / y_{t}$ and aggregate $i_{t} / y_{t}$ in U.S. data over the period 1970 to 2013 (see Figure 2). We use the model decision rules (15) and (16) to construct individual consumption paths for the two types of agents. The baseline simulation and the counterfactual scenario both employ the same time series of distortionary tax wedges and productivity shocks. 
Top Quintile Shares: Model vs. Data

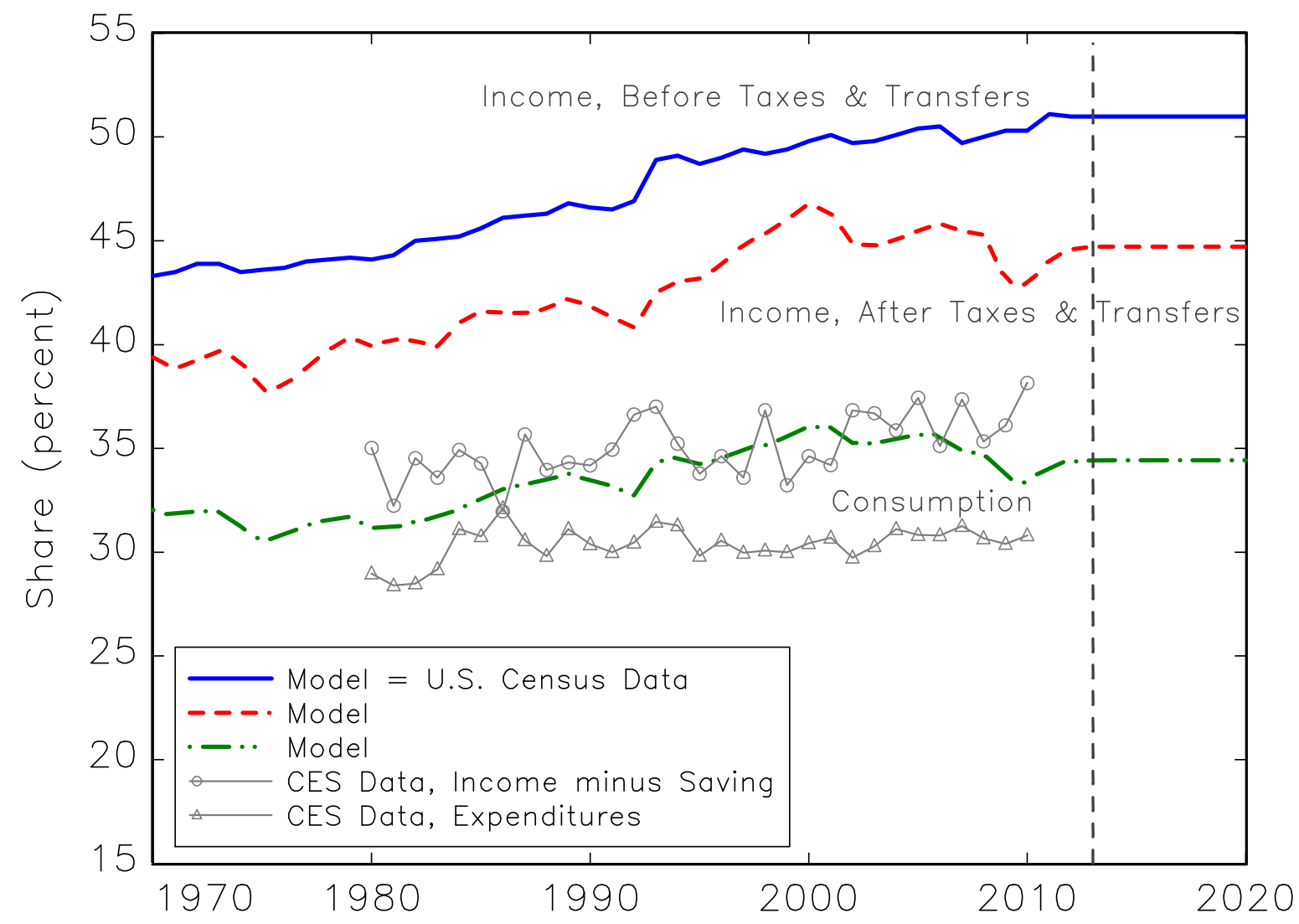

Figure 7: In the baseline simulation, the consumption share of the top quintile (capital owners) rises by less than either their pre-tax or after-tax income share. The top quintile consumption share in the model tracks reasonably well with data from the Consumer Expenditure Survey (CES) for the period 1980 to 2010. The vertical dashed line marks $t=2013$. 

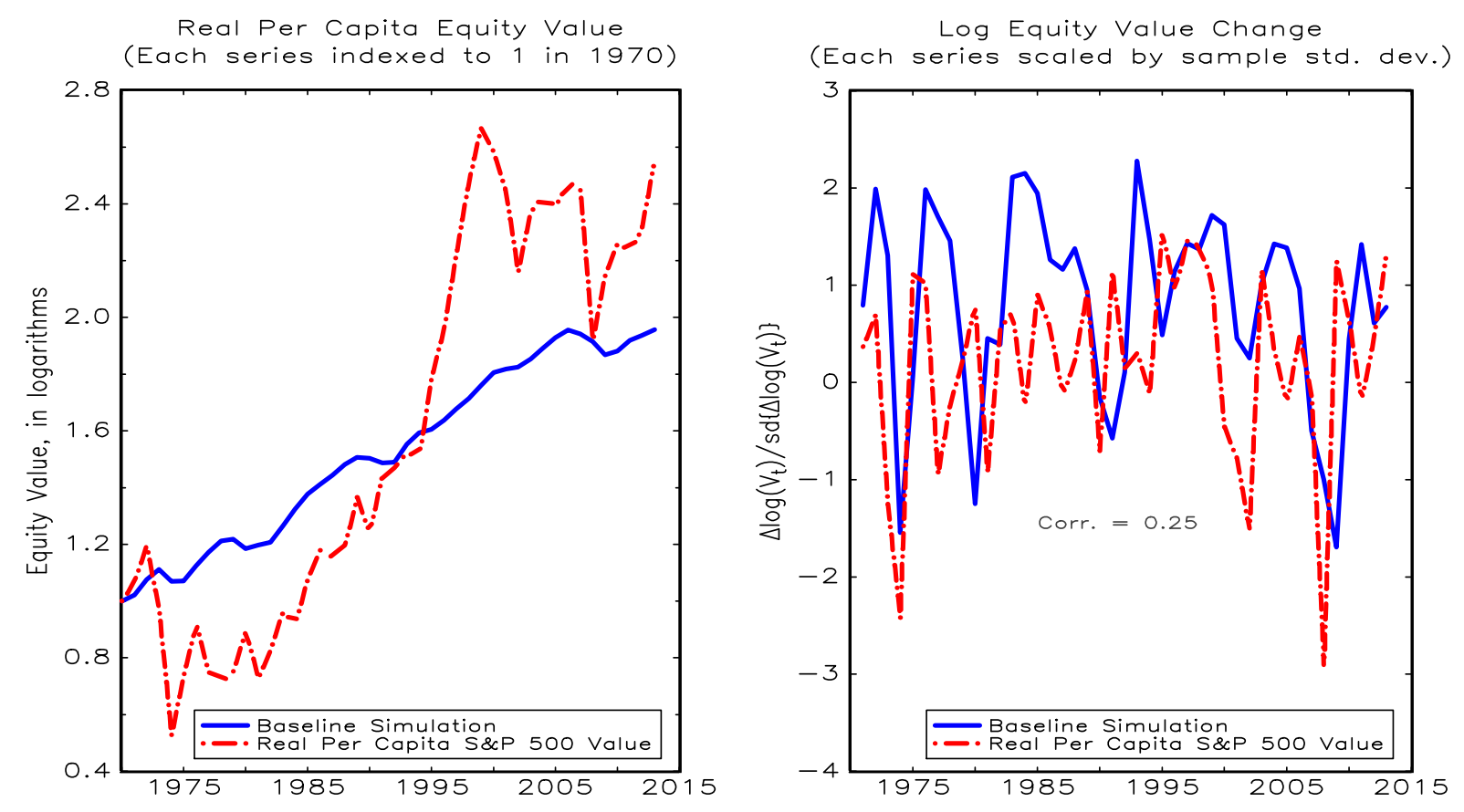

Figure 8: The market value of the $\mathrm{S} \& \mathrm{P} 500$ is far more volatile than the model equity value. Nevertheless, the correlation coefficient between changes in the S\&P 500 market value and changes in the model equity value is 0.25 . 

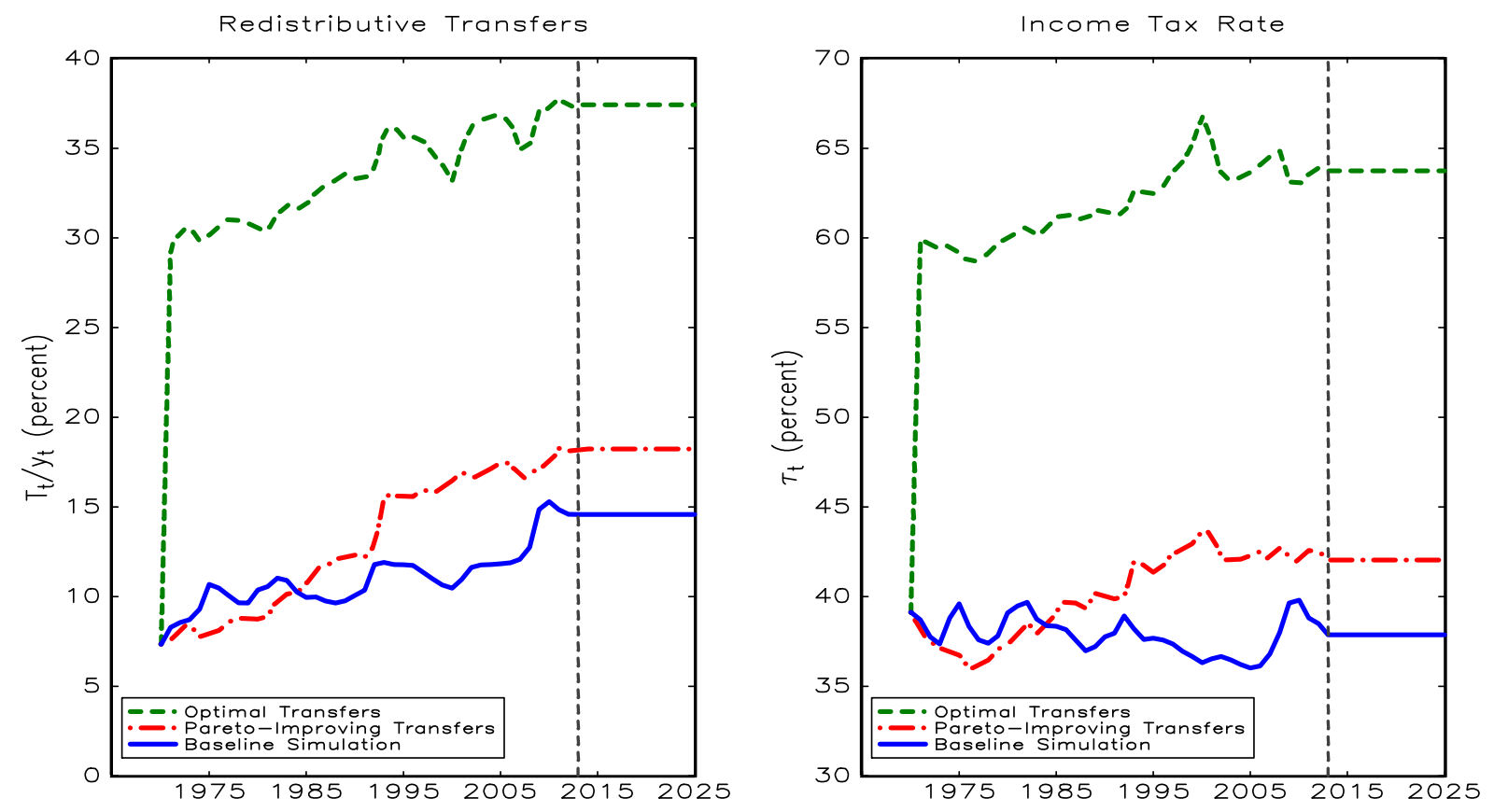

Figure 9: The time series of optimal transfers equalizes agents' marginal utility of consumption each period from 1971 onwards. The time series of Pareto-improving transfers delivers equal welfare gains to capital owners and workers over a long simulation. In both cases, we solve for the income tax rate that is needed to finance the new level transfers. The vertical dashed line marks $t=2013$. 